\title{
The Unprovability of Small Inconsistency
}

\author{
Albert Visser
}

Logic Group

Preprint Series

No. 64

March 1991
Department of Philosophy University of Utrecht Heidelberglaan 2 3584 CS Utrecht The Netherlands 


\title{
The Unprovability of Small Inconsistency
}

\author{
Albert Visser \\ University of Utrecht, Department of Pilosophy, \\ Heidelberglaan 2, 3584CS Utrecht \\ The Netherlands
}

MSC- 1980 classification 03B 15/03F30

Key words and phrases: Provability,

Interpretability, Fragments of Arithmetic 


\title{
The Unprovability of Small Inconsistency
}

\section{A study of local and global interpretability \\ Albert Visser}

\begin{abstract}
We show that a consistent, finitely axiomatized, sequential theory cannot prove its own inconsistency on every definable cut. A corollary is that there are at least three degrees of global interpretability of theories equivalent modulo local interpretability to a consistent, finitely axiomatized, sequential theory $U$.
\end{abstract}

\section{Introduction}

Ever since Gödel, we know that a consistent theory may well prove its own inconsistency. When, however, a theory is so audacious as to actually offer a numeral as code of its own inconsistency proof, then, surely, the theory is inconsistent. In terms of non-standard models it is clear that an object coded by a numeral is extremely small. Thus we could summarize our contrast by saying that a theory may very well consistently prove its own inconsistency but cannot consistently prove its extremely small inconsistency.

In this paper we study a situation which is, in a sense, intermediate between the two extremes. In many arithmetical theories we can obtain definable cuts. Such cuts can play the role of sets of small numbers. For example in theories in which exponentiation is not provably total, there is a cut of numbers $x$ so small that we can prove that $2^{x}$ does exist. Another example: in GB we can define a cut such that we can prove in GB that no element of this cut is an inconsistency proof of ZF. Can we use cuts to provide a notion of smallness such that theories cannot consistently prove their own small inconsistency? At first sight the answer is no. Pavel Pudlák shows that for any consistent arithmetical theory $U$ and for any cut $I$ definable in $U, U$ does not prove its own consistency relativized to $U$ (see Pudlák[85]). Hence $U$ plus the statement that there is an inconsistency proof of $U$ in $I$ is consistent. So numbers on a fixed cut are in the same boat w.r.t. the Gödelian inconsistency phenomenon as just numbers. (This is not really surprising, since numbers on a given cut can always be considered as the numbers of the theory.) Yet we can get the desired effect by quantifying over all definable cuts. Let's say that $\mathrm{U}$ proves its own small inconsistency if for every definable cut $\mathrm{U}$ proves that it contains an inconsistency proof of $\mathrm{U}$. Can a consistent theory prove its own small inconsistency? For some theories like Peano Arithmetic the answer is obviously yes. We show that for a wide class of theories including Robinsons's Arithmetic, GB and $\mathrm{ACA}_{0}$ the answer is no.

The results of our paper throw some light on the contrast between local and global interpretability. Consider the degrees of global interpretability of theories $\mathrm{V}$ equivalent modulo 
local interpretability to a given theory $U$ ordered by global interpretability. We call the degree of V: $\|V\|_{\text {glob }}$ and we call our structure degrees $\operatorname{LOC}_{\text {glob }}(U)$. Pavel Pudlák shows that if, for example, $U=G B$ then there is $d \neq\|U\|_{\text {glob }}$ in $L O C_{g l o b}(U)$ (see Pudlák[85]). We will see that Pudlák's example (for the appropriate class of theories) is the maximum of $\operatorname{LOC}_{\mathrm{glob}}(\mathrm{U})$. An immediate corollary of our result is the modest fact that if (e.g.) $\mathrm{U}=\mathrm{GB}$, then $\mathrm{LOC}_{\mathrm{glob}}(\mathrm{U})$ has at least three elements.

1.1 Contents: Section 2 contains the necessary preliminaries, especially on sequentiality, restricted provability, interpretability and cuts. Section 3 contains various characterizations of local interpretability. Moreover we exhibit two theories that are elements of the maximum of $\mathrm{LOC}_{\mathrm{glob}}(\mathrm{U})$. In section 4 we sharpen our knives: we provide a sharpening of Löb's Theorem which will be used in section 5. An immediate corollary of the results of section 4 is Pudlák's theorem that if $U$ is sequential and finitely axiomatized, then the maximum of $\mathrm{LOC}_{\mathrm{glob}}(\mathrm{U})$ is unequal to $\|U\|_{\text {glob }}$. In section 5 we prove the Tunneling Theorem, our main technical result. The unprovability of small inconsistency is an immediate consequence of the Tunneling Theorem. Section 6 gives the promised result on local and global interpretability: if $f U$ is sequential and finitely axiomatized, then $\mathrm{LOC}_{\mathrm{glob}}(\mathrm{U})$ has at least three elements.

1.2 Prerequisites: The reader should know ((Paris \& Wilkie[87]) or Buss[85]) and (Pudlák[85] or Visser[90]).

1.3 Acknowledgement: The results of this paper are the products of my attempts to understand better what was going on in Pudlák[85] and Krajícek[87]. Jan Krajícek proves in his paper a.o. the unprovability of small inconsistency for $\mathrm{I} \Delta_{0}$. The main difference between Krajícek's approach and ours is the fact that instead of using a powerful result due to Wilkie we use the Tunneling Theorem.

\section{Preliminaries}

2.1 Theories and Provability: Our basic theory in this paper is $I \Delta_{0}+\Omega_{1}$ (see Paris \&Wilkie[87]). It is (modulo some translation work) the same as Buss's theory $S_{2}$ (see Buss[85]). The language of $\mathrm{I} \Delta_{0}+\Omega_{1}$ has constant 0 and function symbols $S,+, \times$. Mostly we will call $\mathrm{I}_{0}+\Omega_{1}$ simply $\Omega$. We will also be looking at $\mathrm{I} \Delta_{0}+\mathrm{EXP}$ and $\mathrm{I} \Delta_{0}+\mathrm{SUPEXP}$, which we will call -if no confusion is possible- simply EXP, respectively SUPEXP.

We will assume that the axiom-set of a theory $\mathrm{T}$ is given by a $\Delta_{1}{ }^{\mathrm{b}}$-predicate (see Buss[1985]). We take this predicate to be part of the identity conditions of the theory. Proof $\mathrm{T}$ is the $\Delta_{1} \mathrm{~b}$ proof predicate based on the predicate defining Ts axiom set.

We write par abus de langage 'Proof $T_{T}\left(u, A\left(x_{1}, \ldots, x_{n}\right)\right)^{\prime}$ for: Proof $T_{T}\left(u,{ }^{r} A\left(\dot{x}_{1}, \ldots, \dot{x}_{n}\right)^{\top}\right)$, here: 
i) all free variables of $\phi$ are among those shown.

ii) $r_{A}\left(\dot{x}_{1}, \ldots, \dot{x}_{n}\right)$ is the "Gödelterm" for $A\left(x_{1}, \ldots, x_{n}\right)$ as defined in Smorynski[85], p43. Here we use instead of the usual numerals the efficient numerals of Paris \& Wilkie[87], so that: $\mathrm{I} \Delta_{0}+\Omega_{1} \vdash \forall \mathrm{x}_{1}, \ldots, \mathrm{x}_{\mathrm{n}} \exists \mathrm{y} \mathrm{A}\left(\dot{\mathrm{x}}_{1}, \ldots, \dot{\mathrm{x}}_{\mathrm{n}}\right)^{\top}=\mathrm{y}$.

$\square_{T} A\left(x_{1}, \ldots, x_{n}\right)$ will stand for: $\operatorname{Prov}_{T}\left({ }^{r} A\left(\dot{x}_{1}, \ldots, \dot{x}_{n}\right)^{\top}\right)$.

Occurrences of terms inside $\square_{T}$ should be treated with some care. Is $\square_{T}(A[t / x])$ intended $c$ $\left(\square_{\mathrm{T}} \mathrm{A}(\mathrm{x})\right)[\mathrm{t} / \mathrm{x}]$ ? We will always use the first, i.e. the small scope reading. In cases where: $U$ proves that $t$ is total and $U \vdash t=x \rightarrow \square_{V} t=x$, the scope distinction may be ignored within $U$ w.r.t. $\square_{V}$. We have: Ur $\left(\square_{V} A(x)\right)[t / x] \leftrightarrow \square_{V}(A[t / x])$.

Some alternative notions of provability will be used in this paper. For these we will make use of the same conventions as for ordinary provability.

2.2 The $\Omega$-hierarchy: We briefly repeat some facts about the $\Omega$-hierarchy and prove some refinements of well known theorems. Since the detailed material of this section is only relevant to theorems 3.2.4 and 3.2.5 which are concerned specifically with the $\Omega$-hierarchy the reader may very well skip this section.

A slight difference with other treatements is that we do not base our choice of concepts on the binary number system but at the ordering of strings:

$\square$ (the empty string), a, b, aa, ab, ba, bb, aaa, aab, ...

This ordering is often called the lexicographic ordering, but since the designation 'lexicographic ordering' is also used for a different ordering (e.g. in Ferrante \& Rackoff[79]), I prefer to call it the Verschuyl Ordering (after a famous Dutch author of dictionaries for crossword puzzlists). We assign Gödelnumbers to strings by counting them along the Verschuyl ordering, counting the empty string as 0.

Define:

$$
\begin{aligned}
& \exp (x):=2 x, \\
& |x|:=\mu y \leq x(x<(\exp (y+1)-1)) \quad \begin{array}{l}
(|x| \text { is the length of the } x-\text { th string in the Verschuyl } \\
\text { Ordering), } \\
(\lambda(x) \text { is the number corresponding to the string of a's } \\
\text { of length }|x| ; 2 . \lambda(x) \text { corresponds to the string of b's } \\
\text { of length }|x|),
\end{array} \\
& \begin{array}{ll}
x \#_{-1} y:=x+y, x \#_{n} y:=\exp \left(|x| \#_{n-1}|y|\right)-1,
\end{array} \\
& \begin{array}{ll}
\omega_{n}(x):=x \#_{n} x .
\end{array}
\end{aligned}
$$

The graphs of each of these functions can be represented in $I \Delta_{0}$ by a $\Delta_{0}$-fomula and $I \Delta_{0}$ proves (under the assumption of existence) the recursion equations. We will use later that the same 
holds for \#(x,y,z):=x\# $\mathrm{z}$.

2.2.1 Facts: $|\exp (\mathrm{x})-1|=x,|\lambda(\mathrm{x})|=|2 . \lambda(\mathrm{x})|=|\mathrm{x}|, \lambda(\mathrm{x}) \leq \mathrm{x} \leq 2 . \lambda(\mathrm{x}), \lambda(\lambda(\mathrm{x}))=\lambda(2 . \lambda(\mathrm{x}))=\lambda(\mathrm{x})$, $x \#_{0} y=\lambda(x) \cdot \lambda(y)+\lambda(x)+\lambda(y)$, for $n \geq 0: x \#_{n} y=\lambda(x) \#_{n} y=x \#_{n} \lambda(y)=\lambda(x) \#_{n} \lambda(y)$ the $\#_{\mathrm{n}}$ are commutative.

Proof: Left to the industrious reader.

\subsubsection{Facts}

i) The $\#_{n}$ are associative.

ii) $\quad x \#_{n} y \leq 1 \#_{n+1} x_{n+1} y$.

iii) $\quad 1 \#_{n+1} y \leq 1 \#_{n} y \#_{n} y$.

Proof: All proofs are by induction on n starting at -1 :

i) The case that $\mathrm{n}=-1$ is trivial,

$$
\begin{aligned}
\left(\mathrm{x}_{\mathrm{n}} \mathrm{y}\right) \#_{\mathrm{n}} \mathrm{z} & =\exp \left(\operatorname{lexp}\left(|\mathrm{x}| \#_{\mathrm{n}-1}|\mathrm{y}|\right)-1\left|\#_{\mathrm{n}-1}\right| \mathrm{z} \mid\right)-1 \\
& =\exp \left(\left(|\mathrm{x}| \#_{\mathrm{n}-1}|\mathrm{y}|\right) \#_{\mathrm{n}-1}|\mathrm{z}|\right)-1 \\
& =\exp \left(|\mathrm{x}| \#_{\mathrm{n}-1}\left(|\mathrm{y}| \#_{\mathrm{n}-1}|\mathrm{z}|\right)\right)-1 \\
& =\exp \left(|\mathrm{x}| \#_{\mathrm{n}-1}\left|\exp \left(|\mathrm{y}| \#_{\mathrm{n}-1}|\mathrm{z}|\right)-1\right|\right)-1 \\
& =\#_{\mathrm{n}}\left(\mathrm{y} \#_{\mathrm{n}} \mathrm{z}\right) .
\end{aligned}
$$

ii) $\quad 1 \#_{0} x \#_{0} y=\exp (1+|x|+|y|)-1=2 \cdot(\lambda(x) \cdot \lambda(y)+\lambda(x)+\lambda(y))+1 \geq 2 \cdot \lambda(x)+2 \cdot \lambda(y) \geq x+y$, $1 \#_{n} \mathrm{x} \#_{\mathrm{n}} \mathrm{y}=\exp \left(1 \#_{\mathrm{n}-1}|\mathrm{x}| \#_{\mathrm{n}-1}|\mathrm{y}|\right)-1 \geq \exp \left(|\mathrm{x}| \#_{\mathrm{n}-2}|\mathrm{y}|\right)-1=|\mathrm{x}| \#_{\mathrm{n}-1}|\mathrm{y}|$.

ii) $\quad 1 \#_{0} \mathrm{y}=2 \cdot \lambda(\mathrm{y})+1 \leq 2 \cdot \mathrm{y}+1$, $1 \#_{n} y=\exp \left(1 \#_{n-1}|y|\right)-1 \leq \exp \left(1 \#_{n-2}|y| \#_{n-2}|y|\right)-1=1 \#_{n-1}|y| \#_{n-1}|y|$.

The various facts of 2.2.1 and 2.2.2 are (in appropriate formulations) verifiable in $\mathrm{I}_{0}$. Let's say that a set of numbers $X$ is $n$-closed if: $1 \in X, X$ is closed under $\#_{n}$ and $X$ is downwards closed under $\leq$. If a theory $U$ can verify that the set given by formula I is 1-closed, we say that $\mathrm{I}$ is a $U$-cut.

2.2.3 Lemma: In $\mathrm{I}_{0}$ (extended with a unary predicate symbol $\mathrm{X}$ added) we can verify:

i) If $X$ is $n$-closed, then $X$ is $k$-closed for all $k \leq n$.

ii) If $X n$-closed $(n \geq 0)$, then $\{x \mid \exp (x) \in X\}$ is (n-1)-closed.

Proof: (i) Immediate by 2.2.2(ii). (ii) is left is to the reader.

2.2.4 Construction: We construct in $\mathrm{I} \Delta_{0}$ (by a method due to Solovay) provably $\mathrm{n}$-closed sets $I_{n}$ such that $I_{n} \subseteq X$, supposing that $X$ is (-1)-closed. Suppose $X$ is $(-1)$-closed. Let $I_{-1}:=X$. $I_{n+1}:=\left\{x \in I_{n} \mid \forall y \in I_{n} x \#_{n+1} y \in I_{n}\right\}$. Suppose $I_{n}$ is $n$-closed. Consider $u, v \in I_{n+1}$ and $y \in I_{n}$ then: $\left(u \#_{n+1} v\right) \#_{n+1} y=u \#_{n+1}\left(v \#_{n+1} y\right)$. 
Clearly $\left(v \#_{n+1} y\right) \in I_{n}$ and hence $u \#_{n+1}\left(v \#_{n+1} y\right) \in I_{n}$. So we may conclude that $u \#_{n+1} v \in I_{n+1}$. It is easily seen that downwards closure under $\leq$ is preserved. Finally since $1 \#_{n+1} y \leq 1 \#_{n} y \#_{n} y$ and for any $y \in I_{n}: 1 \#_{n} y \#_{n} y \in I_{n}$, we find that $1 \in I_{n}$.

2.2.5 Estimate: For later use we estimate the number of symbols in the definition of $I_{n}$ in case the definitions are written down as economically as possible. Par abus de langage we write $|\mathrm{A}|$ for the number of symbols in expression $\mathrm{A}$. Using the fact that a uniform definition of the $\#_{n}$ can be given we see that the definition of $I_{n+1}$ can be brought in the form $\Phi\left(n, I_{n}\right)$, where $\Phi(v, Y)$ is a fixed formula in the language of arithmetic extended with unary predicate symbol Y. As is well known we can use a trick of Ferrante \& Rackoff (see Ferrante \& Rackoff[79]) to rewrite $\Phi$ in such a way that $\mathrm{Y}$ occurs only once. Let's assume that $\Phi$ is written in this economical form. It follows that $\left|\Phi\left(n, I_{n}\right)\right|=\left|I_{n}\right|+k \cdot|n|+p$ for certain $k$ and $p$, so $\left|I_{n}\right|$ can be estimated by $\mathrm{m} . \mathrm{n}^{2}+\mathrm{s}$ for certain $\mathrm{m}, \mathrm{s}$. (The trick by Ferrante \& Rackoff as it stands works only if $\leftrightarrow$ is present in the language. However Solovay discovered a further trick to overcome this restriction. Solovay has shown how his method works to me in correspondence. Solovay's discovery is mentioned by Ferrante \& Rackoff in their book. Recently Pudlák independently discovered a method to eliminate the use of $\leftrightarrow$.)

Using our estimate for the $\left|I_{n}\right|$, we can estimate $\left|p_{n}\right|$, where $p_{n}$ is the (code of the) proof that $I_{n}$ is closed under $\#_{n}$ by $m^{\prime} \cdot n^{3}+s^{\prime}$. This estimate is entirely routine. (Note that we need an estimate of e.g. the proof that $\#_{n}$ is associative.)

2.3 Sequential Theories: We briefly repeat some essential facts about sequential theories. A sequential theory can express and prove (possibly in a relational language) the following facts about sequences:

a) $\quad<$, the empty sequence, exists, and $\operatorname{Lth}(<>)=0$

b) $\forall \sigma \in \operatorname{Seq} \exists \mathrm{i} \in \mathrm{N}\left(\operatorname{Lth}(\sigma)=\mathrm{i} \wedge \forall \mathrm{j}<\mathrm{i} \exists \mathrm{x} \sigma_{\mathrm{j}}=\mathrm{x}\right)$

c) $\forall \sigma \in \operatorname{Seq} \forall x \exists \tau \in \operatorname{Seq}\left(\operatorname{Lth}(\tau)=\operatorname{Lth}(\sigma)+1 \wedge \forall j<\operatorname{Lth}(\sigma) \tau_{\mathrm{j}}=\sigma_{\mathrm{j}} \wedge \tau_{\mathrm{Lth}(\sigma)}=\mathrm{x}\right)$

Here $\mathrm{N}$ is a set of 'numbers' available in the theory which satisfy $\mathrm{Q}$ (i.e. Robinson's Arithmetic). We write $\sigma^{* *} \mathrm{x}$ for the $\tau$ guaranteed in (c).

It is easily seen that $\sigma \mathrm{E} \tau: \Leftrightarrow \operatorname{Lth}(\sigma)=\operatorname{Lth}(\tau) \wedge \forall \mathrm{i}<\operatorname{Lth}(\sigma) \sigma_{\mathrm{i}}=\tau_{\mathrm{i}}$, is an equivalence relation on sequences. By dividing in out precisely when we treat objects as sequences we see that we may assume that two sequences $\sigma, \tau$ are equal iff $\sigma E \tau$. Thus we may always add:

d) $\forall \sigma, \tau \in \operatorname{Seq}(\sigma=\tau \leftrightarrow \sigma E \tau)$

We show that we may assume that our sequences are closed under restriction and concatenation. Define: $\operatorname{Res}(\sigma, \mathrm{i}, \tau): \leftrightarrow \operatorname{Lth}(\tau)=\operatorname{Min}(\operatorname{Lth}(\sigma), i) \wedge \forall j<\operatorname{Lth}(\tau) \sigma_{\mathrm{j}}=\tau_{\mathrm{j}}$. It is easy to see that $\operatorname{Res}$ defines a (partial) function, so we may write $\sigma\lceil i \cong \tau$ for $\operatorname{Res}(\sigma, i, \tau)$. 
Let $X:=\{i \in N \mid \forall \sigma \in$ Seq $\exists \tau \in$ Seq $\sigma\lceil i \simeq \tau\}$. Clearly $0 \in X$. Suppose $\sigma l i \downarrow$. If $i<L \operatorname{th}(\sigma)$ we have: $\sigma l i+1 \cong \sigma i^{* *} \sigma_{i}$. Otherwise $\sigma l i=\sigma$. Ergo $X$ contains 0 and is closed under successor. Let $N_{0}$ be a shortening of $X$ that is closed under.+ Seq $_{0}:=\left\{\sigma \in \operatorname{Seq} \mid L\right.$ th $\left.(\sigma) \in N_{0}\right\}$. Clearly $N_{0}$ and $S q_{0}$ satisfy (a),(b),(c),(d). Moreover $\uparrow$ is total on $\mathrm{Seq}_{0}$ and $\mathrm{N}_{0}$.

Define:

$$
\begin{aligned}
\operatorname{Conc}(\sigma, \rho, \tau): \leftrightarrow & \operatorname{Lth}(\tau)=\operatorname{Lth}(\sigma)+\operatorname{Lth}(\rho) \wedge \\
& \forall i<\operatorname{Lth}(\sigma) \sigma_{i}=\tau_{i} \wedge \forall j<\operatorname{Lth}(\rho) \rho_{j}=\tau_{L} \operatorname{Lth}(\sigma)+j
\end{aligned}
$$

Since Conc is evidently a partial function we write $\sigma^{*} \rho \cong \tau$.

Suppose $\sigma^{*} \rho \cong \tau$. As is easily seen: $\sigma^{*}\left(\rho^{* *} \mathrm{x}\right) \cong \tau^{* *} \mathrm{x}$.

Let $Y:=\left\{x \in N_{0} \mid \forall \rho \in \operatorname{Seq}_{0} \operatorname{Lth}(\rho)=x \rightarrow \forall \sigma \in \operatorname{Seq}_{0} \exists \tau \in \operatorname{Seq}_{0} \sigma * \rho \equiv \tau\right\}$.

As is easily seen $0 \in \mathrm{Y}$. Suppose $\mathrm{x} \in \mathrm{Y}$. We show that $\mathrm{x}+1 \in \mathrm{Y}$. Consider $\rho \in \mathrm{Seq}_{0}$ with $\operatorname{Lth}(\rho)=x+1$. Clearly $\operatorname{Lth}\left(\rho\lceil x)=x\right.$ and $\rho=\rho\left\lceil x * * \rho_{x}\right.$. Consider any $\sigma \in \operatorname{Seq}_{0}$. Let $\sigma^{*} \rho\lceil x \equiv v$. Then $\sigma^{*} \rho=\sigma^{*}\left(\rho{ }^{\prime} x^{* *} \rho_{x}\right) \equiv v^{* *} \rho_{x}$.

Let $N_{1}$ be some shortening of $Y$ such that $N_{1}$ satisfies $\Omega$ and let $\operatorname{Seq}_{1}:=\left\{\sigma \in \operatorname{Seq} \mid \operatorname{Lth}(\sigma) \in N_{1}\right\}$.

We see that we may add to our list:

e) $\forall \mathrm{i} \in \mathrm{N} \forall \sigma \in \operatorname{Seq} \exists \tau \in$ Seq $\sigma \mathrm{i}_{\mathrm{i}} \tau \tau$

f) $\forall \sigma, \tau \in \operatorname{Seq} \exists p \in \operatorname{Seq} \sigma^{*} \tau \cong \rho$

g) $\Omega^{\mathrm{N}}$.

Standing assumption: We will only consider sequential theories with numbers satisfying (a)-(g).

2.4 Restricted Provability: In this section we treat our notion of restricted provability. Many of the details on our measure of complexity $\rho$ and the satisfaction predicates $S_{n} t_{n}$ are not essential for understanding the rest of the paper and could be skipped. What counts is that the details can be filled in in some way. The main things for the reader to understand are these: $\rho$ is depth of quantifier changes; $S_{a} t_{n}$ is a satisfaction relation for $A$ with $\rho(A) \leq n ; \operatorname{Proof}_{U, n}$ is a proof-relation for proofs where one considers only axioms $<\mathrm{n}$ and where in the proof only formulas A with $\rho(A) \leq|n|$ occur. The reader should at least appreciate the content of 2.4.22.4.8. 
Let $U$ be a sequential theory in a language $L$ with finitely many constant symbols, finitely many relation symbols and finitely many function symbols.

Most of our notations for syntactical operations are self evident. $\operatorname{Var}(\mathrm{u})$ is the $u$-the variable. We assume that the variables are coded with their indices in binary such that we have $|\operatorname{Var}(\mathrm{u})| \leq \mathrm{m} .|\mathrm{u}|+\mathrm{k}$ for standard $\mathrm{m}, \mathrm{k}$. Exqu(u,v) is the code of the result adding existential quantification with the $u$-th variable to the formula coded by $v$. More formally: Exqu(u,v):= $\exists * \operatorname{Var}(u) * v$ (here we use * for the arithmetization of concatenation of strings). We code total functions with range almost everywhere 0 in some suitable way. To express that $x$ codes a function in this sense we write: Func(x). [x] u means the result of application of the function coded by $x$ to $u$. $x[u: z]$ means: the code of the function that gives the same values as the function coded by $x$ except on $u$ where it gives $z$. We can arrange it so that $[x] u$ and $x[u: z]$ represent provably total functions. (We cannot use sequences to code our functions (in the naive way) precisely because this would make $x[u: z]$ grow to fast, since we would have to "fill in" explicitely all the values below u. E.g. $<>$ [u:1] would be $<0,0, \ldots 0,1>$ a sequence of length $\mathrm{u}+1$, so $<>[\mathrm{u}: 1]$ would be exponential in $\mathrm{u}$.)

We define $\rho$ on $\{0,1\}^{2} \times$ FORM. $\rho$ counts the "depth of quantifierchanges". The first component is 0 when the formula under consideration is stipulated to be on a positive place, 1 when the place is considered negative. The second component is 0 when we are in the existential mode, i.e. the last quantifier counted is supposed to be existential, and thus when the next quantifier we meet is again existential it need not be counted. Similarly when the second component is 1 , we are in the universal mode.

$\rho(i, j, x)=0$ if $x$ is an atom,

$\rho(i, j, \operatorname{Conj}(x, y))=\rho(i, j, \operatorname{Disj}(x, y))=\operatorname{Max}\{\rho(i, j, x), \rho(i, j, y)\}$,

$\rho(i, j, \operatorname{Neg}(x))=\rho(1-i, 1-j, x)$

$\rho(0, j, \operatorname{Impl}(x, y))=\operatorname{Max}\{\rho(1,1-j, x), \rho(0, j, y)\}, \rho(1, j, \operatorname{Impl}(x, y))=\operatorname{Max}\{\rho(1, j, x), \rho(0,1-j, y)\}$,

$\rho(i, j, \operatorname{Eq}(x, y))=\operatorname{Max}\{\rho(1-i, 1-j, x), \rho(i, j, x), \rho(1-i, 1-j, y), \rho(i, j, y)\}$,

$\rho(\mathrm{i}, 0, \operatorname{Exqu}(\mathrm{x}, \mathrm{y}))=\rho(\mathrm{i}, 0, y), \rho(\mathrm{i}, 1, \operatorname{Exqu}(\mathrm{x}, \mathrm{y}))=\rho(\mathrm{i}, 0, \mathrm{y})+1$,

$\rho(i, 0, \operatorname{Unqu}(x, y))=\rho(i, 1, y)+1, \rho(i, 1, \operatorname{Exqu}(x, y))=\rho(i, 1, y)$.

$\rho(x):=\rho(0,0, x)$,

$x \in E_{n}: \leftrightarrow(F O R(x) \wedge \rho(x) \leq n) . x \in U_{n}: \leftrightarrow(F O R(x) \wedge \rho(0,1, x) \leq n)$.

$\operatorname{Proof}_{U, n}(p, x): \leftrightarrow \operatorname{Proof}_{U}(p, x) \wedge \forall i<L$ th $(p)\left((p)_{i} \in E_{|n|} \wedge\left((p)_{i} \in \alpha_{U} \rightarrow(p)_{i}<n\right)\right.$.

Note that in restricted provability we ask $\rho\left((\mathrm{p})_{\mathrm{i}}\right) \leq \mathrm{nl}$, this is because in $\Omega$ for any existing formula $A: \rho(A) \in S N:=\left\{x \mid 2^{x}\right.$ exists $\}$. The present formulation will simplify the statement of several theorems.

\subsubsection{Examples}

$$
\rho(0,0, \operatorname{Neg}(\operatorname{Exqu}(x, \operatorname{Neg}(y))))=\rho(1,1, \operatorname{Exqu}(x, \operatorname{Neg}(y)))=
$$




$$
\begin{aligned}
& \rho(1,0, \operatorname{Neg}(y))+1=\rho(0,1, y)+1=\rho(0,0, \operatorname{Unqu}(x, y)), \\
& \rho(0,0, \operatorname{Conj}(\operatorname{Impl}(x, y), \operatorname{Impl}(y, x)))= \\
& \operatorname{Max}\{\rho(0,0, \operatorname{Impl}(x, y)), \rho(0,0, \operatorname{Impl}(y, x))\}= \\
& \operatorname{Max}\{\operatorname{Max}\{\rho(1,1, x), \rho(0,0, y)\}, \operatorname{Max}\{\rho(0,0, x), \rho(1,1, y)\}\}= \\
& \operatorname{Max}\{\rho(1,1, x), \rho(0,0, y), \rho(0,0, x), \rho(1,1, y)\}=\rho(0,0, \operatorname{Eq}(x, y))
\end{aligned}
$$

In our definition of Sat we will assume (for the sake of readability) that the language has only one binary relation symbol $R$, one unary function symbol $F$, one binary functionsymbol $G$ and one constant $\mathrm{c}$. Of course the general case is completely analogous. The definition of $\mathrm{Sat}_{\mathrm{n}+1}$ will call on $\mathrm{Sat}_{n}$ as soon as we swich from the existential mode to the universal mode. The first component of the elements of our witnessing sequences will be the first component $u$ of the $\rho(u, v, x)$ under consideration. If we evaluate a term we make the first component 2 .

$$
\begin{aligned}
& \operatorname{Sat}_{n}(r, x): \leftrightarrow \operatorname{Func}(r) \wedge x \in E_{n} \wedge \\
& \exists w\left(\operatorname{Seq}(w) \wedge(w)_{\text {lth }(w)-1}=<0, r, x>\wedge \forall i<L \text { th }(w) \exists s, y<w\right. \\
& \left((\mathrm{w})_{\mathrm{i}}=<0, \mathrm{~s}, \mathrm{y}>\wedge \exists \mathrm{u}, \mathrm{v} \leq \mathrm{y}(\right. \\
& (\operatorname{At}(y) \wedge y=\operatorname{Comp}(\underline{R}, \mathrm{u}, \mathrm{v}) \wedge \exists j, \mathrm{k}<\mathrm{i} \exists \mathrm{p}, \mathrm{q}<\mathrm{w} \\
& \left((w)_{j}=<2, s, u, p>\wedge(w)_{k}=<2, s, v, q>\wedge R(p, q)\right) \vee \\
& \left(\mathrm{y}=\operatorname{Conj}(\mathrm{u}, \mathrm{v}) \wedge \exists \mathrm{j}, \mathrm{k}<\mathrm{i}\left((\mathrm{w})_{\mathrm{j}}=<0, \mathrm{~s}, \mathrm{u}>\wedge(\mathrm{w})_{\mathrm{k}}=<0, \mathrm{~s}, \mathrm{v}>\right)\right) \vee \\
& \left(y=\operatorname{Disj}(u, v) \wedge \exists j<i\left((w)_{j}=<0, s, u>v(w)_{j}=<0, s, v>\right)\right) \vee \\
& \left(y=\operatorname{Impl}(u, v) \wedge \exists j<i\left((w)_{j}=<1, s, u>\vee(w)_{j}=<0, s, v>\right)\right) \vee \\
& \left(\mathrm{y}=\operatorname{Neg}(\mathrm{u}) \wedge \exists \mathrm{j}<\mathrm{i}\left((\mathrm{w})_{\mathrm{j}}=<1, \mathrm{~s}, \mathrm{u}>\right) \vee\right. \\
& \left(y=\operatorname{Exqu}(u, v) \wedge \exists z \exists j<i(w)_{j}=<0, s[u: z], v>v\right. \\
& \left.\left(\mathrm{y}=\operatorname{Unqu}(\mathrm{u}, \mathrm{v}) \wedge \neg \operatorname{Sat}_{\mathrm{n}-1}(\mathrm{~s}, \mathrm{Neg}(\mathrm{y}))\right)\right) \vee \\
& \left((\mathrm{w})_{\mathrm{i}}=<1, \mathrm{~s}, \mathrm{y}>\wedge \exists \mathrm{u}, \mathrm{v} \leq \mathrm{y}(\right. \\
& (\operatorname{At}(y) \wedge y=A p p(\underline{R}, u, v) \wedge \exists j, k<i \quad \exists p, q<w \\
& \left((\mathrm{w})_{\mathrm{j}}=<2, \mathrm{~s}, \mathrm{u}, \mathrm{p}>\wedge(\mathrm{w})_{\mathrm{k}}=<2, \mathrm{~s}, \mathrm{v}, \mathrm{q}>\wedge \neg \mathrm{R}(\mathrm{p}, \mathrm{q})\right) \vee \\
& \left(\mathrm{y}=\operatorname{Conj}(\mathrm{u}, \mathrm{v}) \wedge \exists \mathrm{j}<\mathrm{i}\left((\mathrm{w})_{\mathrm{j}}=<1, \mathrm{~s}, \mathrm{u}>\vee(\mathrm{w})_{\mathrm{j}}=<1, \mathrm{~s}, \mathrm{v}>\right)\right) \vee \\
& \left(\mathrm{y}=\operatorname{Disj}(\mathrm{u}, \mathrm{v}) \wedge \exists \mathrm{j}, \mathrm{k}<\mathrm{i}\left((\mathrm{w})_{\mathrm{j}}=<1, \mathrm{~s}, \mathrm{u}>\wedge(\mathrm{w})_{\mathrm{k}}=<1, \mathrm{~s}, \mathrm{v}>\right)\right) \vee \\
& \left(\mathrm{y}=\operatorname{Impl}(\mathrm{u}, \mathrm{v}) \wedge \exists \mathrm{j}, \mathrm{k}<\mathrm{i}\left((\mathrm{w})_{\mathrm{j}}=<0, \mathrm{~s}, \mathrm{u}>\wedge(\mathrm{w})_{\mathrm{k}}=<1, \mathrm{~s}, \mathrm{v}>\right)\right) \vee \\
& \left(y=\operatorname{Neg}(u) \wedge \exists j<i\left((w)_{j}=<0, s, u>\right) \vee\right. \\
& \left(\mathrm{y}=\operatorname{Exqu}(\mathrm{u}, \mathrm{v}) \wedge \neg \mathrm{Sat}_{\mathrm{n}-1}(\mathrm{~s}, \mathrm{y})\right) \vee \\
& \left.\left.\left(\mathrm{y}=\operatorname{Unqu}(\mathrm{u}, \mathrm{v}) \wedge \exists \mathrm{z} \exists \mathrm{j}<\mathrm{i}(\mathrm{w})_{\mathrm{j}}=<1, \mathrm{~s}[\mathrm{u}: \mathrm{z}], \mathrm{v}>\right)\right)\right) \vee \exists \mathrm{p}<\mathrm{w} \\
& \left((w)_{i}=<2, s, y, p>\wedge \exists u, v \leq y(\right. \\
& (\mathrm{y}=\operatorname{Var}(\mathrm{u}) \wedge[\mathrm{s}] \mathrm{u}=\mathrm{p}) \vee \\
& (\mathrm{y}=\underline{\mathrm{c}} \wedge \mathrm{p}=\mathrm{c}) \vee \\
& \left(y=A p p(\underline{F}, u) \wedge \exists j<i \quad \exists q<w\left((w)_{j}=<2, s, u, q>\wedge p=F(q)\right)\right) \vee \\
& (\mathrm{y}=A \mathrm{pp}(\underline{\mathrm{G}}, \mathrm{u}, \mathrm{v}) \wedge \exists \mathrm{j}, \mathrm{k}<\mathrm{i} \exists \mathrm{q}, \mathrm{r}<\mathrm{w} \\
& \left.\left.\left((\mathrm{w})_{\mathrm{j}}=<2, \mathrm{~s}, \mathrm{u}, \mathrm{q}>\wedge(\mathrm{w})_{\mathrm{k}}=<2, \mathrm{~s}, \mathrm{v}, \mathrm{r}>\wedge \mathrm{p}=\mathrm{G}(\mathrm{q}, \mathrm{r})\right)\right)\right)
\end{aligned}
$$


$\operatorname{Val}(r, x) \cong z: \leftrightarrow \operatorname{Func}(r) \wedge \operatorname{TER}(\mathbf{x}) \wedge$

$\exists w\left(\operatorname{Seq}(w) \wedge(w)_{1 \text { th }(w)-1}=<2, r, x, z>\wedge \forall i<l\right.$ th $(w)$

$\exists y<w \exists p<w\left((w)_{i}=<2, r, y, p>\wedge \exists u, v \leq y(\right.$

$(\mathrm{y}=\operatorname{Var}(\mathrm{u}) \wedge[\mathrm{r}] \mathrm{u}=\mathrm{p}) \vee$

$(\mathrm{y}=\underline{\mathrm{c}} \wedge \mathrm{p}=\mathrm{c}) \vee$

$\left(\mathrm{y}=\operatorname{App}(\mathrm{F}, \mathrm{u}) \wedge \exists j<\mathrm{i} \exists \mathrm{q}<\mathrm{w}\left((\mathrm{w})_{\mathrm{j}}=<2, \mathrm{r}, \mathrm{u}, \mathrm{q}>\wedge \mathrm{p}=\mathrm{F}(\mathrm{q})\right)\right) \vee$

$(\mathrm{y}=\mathrm{App}(\underline{\mathrm{G}}, \mathrm{u}, \mathrm{v}) \wedge \exists \mathrm{j}, \mathrm{k}<\mathrm{i} \exists \mathrm{q}, \mathrm{t}<\mathrm{w}$

$\left.\left.\left((w)_{j}=<2, r, u, q>\wedge(w)_{k}=<2, r, v, \downarrow>\wedge p=G(q, t)\right)\right)\right)$,

$\operatorname{Sat}_{n}(r, x): \leftrightarrow \neg \operatorname{Sat}_{n}(r, \operatorname{Neg}(\mathbf{x}))$

We use the trick of Ferrante \& Rackoff (see 2.2.5) to rewrite the definition of Sat $\mathrm{n}_{\mathrm{n}+1}$ in such a way that $S a_{n}$ occurs only once. It follows that $\left|{ }^{\top} \underline{S a t}_{n}(u, v)^{\top}\right|=k \cdot n+m$ for certain standard $k$ and $\mathrm{m}$, so ' $\underline{\mathrm{Sat}}_{\underline{n}}(\mathrm{u}, \mathrm{v})^{\top}$ ' is of order $\mathrm{p} .2^{\mathrm{k} . \mathrm{n}}$ for standard $\mathrm{p}, \mathrm{k}$.

\subsubsection{Fact}

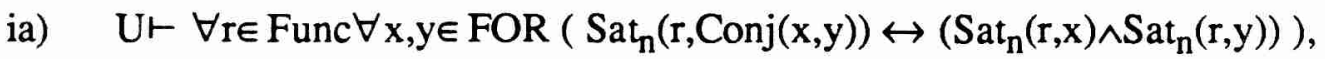

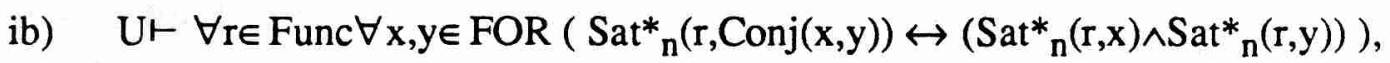

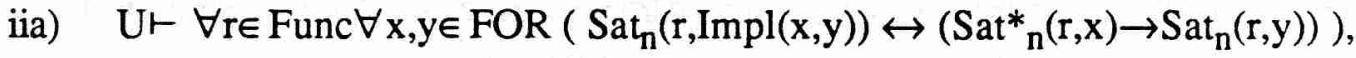

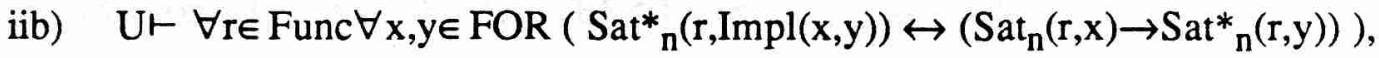

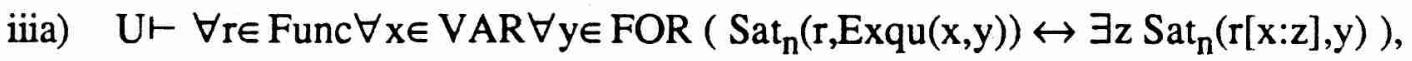

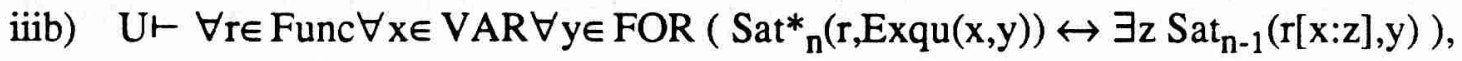


$\left.\left(\operatorname{Val}(r, x) \downarrow_{\wedge} \operatorname{Val}(r, y) \downarrow \wedge R(\operatorname{Val}(r, x), \operatorname{Val}(r, y))\right)\right)$

v) $\mathrm{U} \vdash \forall \mathrm{r} \in \operatorname{Func} \forall \mathrm{x}, \mathrm{y} \in \operatorname{TER}(\operatorname{Val}(\mathrm{r}, \mathrm{App}(\mathrm{F}, \mathrm{x})) \cong \mathrm{y}) \leftrightarrow \exists \mathrm{z}(\operatorname{Val}(\mathrm{r}, \mathrm{x}) \cong \mathrm{z} \wedge \mathrm{F}(\mathrm{z})=\mathrm{y}))$ etc.

Proof: The proofs are routine and boring. We treat four cases. Reason in U.

ia) Consider $r \in$ Func and $x, y \in$ FOR. Suppose $\operatorname{Sat}_{n}(r, \operatorname{Conj}(x, y))$. Let $w$ be the witnessing sequence. Since $(w)_{L t h(w)-1}=<0, r, \operatorname{Conj}(x, y)>$, there are $i, j<L$ th $(w)-1$ with $(w)_{i}=<0, r, x>$ and $(w)_{j}=<0, r, y>$. It is easily seen that $w l^{i+1}$ and $w\left\lceil j+1\right.$ are witnesses for respectively $\operatorname{Sat}_{n}(r, x)$, $\operatorname{Sat}_{\mathrm{n}}(\mathrm{r}, \mathrm{y})$. Conversely assume $\mathrm{w}_{0}, \mathrm{w}_{1}$ are witnessing sequences for respectively $\operatorname{Sat}_{\mathrm{n}}(\mathrm{r}, \mathrm{x})$, $\operatorname{Sat}_{\mathrm{n}}(\mathrm{r}, \mathrm{y})$. As is easily seen $\mathrm{w}_{0}{ }^{*} \mathrm{w}_{1}{ }^{* *}<0, \mathrm{r}, \operatorname{Conj}(\mathrm{x}, \mathrm{y})>$ is a witnessing sequence for $\mathrm{Sat}_{\mathrm{n}}(\mathrm{r}, \operatorname{Conj}(\mathrm{x}, \mathrm{y}))$.

iia) Consider $r \in$ Func and $x, y \in F O R$. Suppose $\operatorname{Sat}_{n}(r, \operatorname{Impl}(x, y))$. Let $w$ be the witnessing sequence. Since $(w)_{L t h(w)-1}=<0, r, \operatorname{Impl}(x, y)>$, there is an $i<L$ th $(w)-1$ with $(w)_{i}=<1, r, x>$ or $(w)_{i}=<0, r, y>$. Suppose $(w)_{i}=<1, r, x>$. Since $w^{l}(i+1)^{* *}<0, r, \operatorname{Neg}(x)>$ witnesses $\operatorname{Sat}_{n}(r, \operatorname{Neg}(x))$, we find $\neg \operatorname{Sat}_{n} *(r, x)$. Suppose $(w)_{i}=<0, r, y>$. Clearly $w \uparrow(i+1)$ witnesses 
$\operatorname{Sat}_{n}(r, y)$. Conversely assume $\neg \operatorname{Sat}_{n}{ }^{*}(r, x)$ or $\operatorname{Sat}_{n}(r, y)$. In the first case we have $\operatorname{Sat}_{n}(r, \operatorname{Neg}(x))$. Let $u$ be a witnessing sequence. Since $(u)_{L t h(u)-1}=<0, r, N e g(x)>$, for some

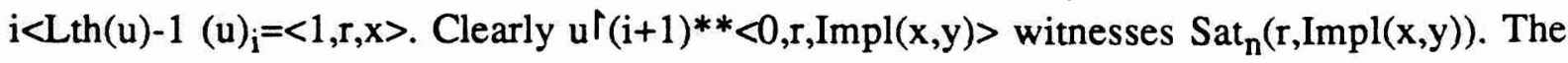
case of $\operatorname{Sat}_{n}(\mathrm{r}, \mathrm{y})$ is left to the reader.

iiia) Consider $r \in$ Func, $x \in$ VAR, $y \in$ FOR and suppose $\operatorname{Sat}_{n}(r, \operatorname{Exqu}(x, y))$. Let $w$ be a witness of $\operatorname{Sat}_{n}(r, \operatorname{Exqu}(x, y))$. Then for some $z$ and some $i<l t h(r)-1:(w)_{i}=<0, r[x: z], y>$. It follows that $w^{\top}(i+1)$ witnesses $S_{a t}(r[x: z], y)$. Conversely suppose $S a t_{n}(r[x: z], y)$. Let v be a witness. Then $\mathrm{v}^{* *}<1, \mathrm{r}, \operatorname{Exqu}(\mathrm{x}, \mathrm{y})>$ witnesses $\operatorname{Sat}_{\mathrm{n}}(\mathrm{r}, \operatorname{Exqu}(\mathrm{x}, \mathrm{y}))$.

iiib) Consider $r \in$ Func, $x \in V A R, y \in F O R$. By (iiia) it is sufficient to show:

$$
\operatorname{Sat}_{n}(r, \operatorname{Exqu}(x, y)) \leftrightarrow \operatorname{Sat}_{n-1}(r, \operatorname{Exqu}(x, y)) .
$$

First suppose $\neg \operatorname{Sat}_{n}{ }_{n}(r, \operatorname{Exqu}(x, y))$, i.e. $\operatorname{Sat}_{n}(r, \operatorname{Neg}(\operatorname{Exqu}(x, y)))$. For some $i<\operatorname{Lth}(r)-1$ we have: $(r)_{i}=<1, r, \operatorname{Exqu}(x, y)>$ and $\neg \operatorname{Sat}_{n-1}(r, \operatorname{Exqu}(x, y))$.

Conversely suppose $\neg \operatorname{Sat}_{n-1}(r, \operatorname{Exqu}(x, y))$. Then $<<1, r, \operatorname{Exqu}(x, y)>,<0, r, \operatorname{Neg}(\operatorname{Exqu}(x, y))>>$

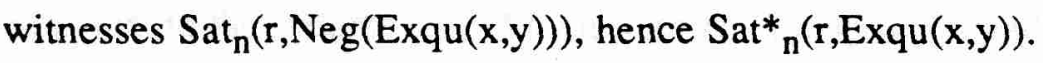

\subsubsection{Fact}

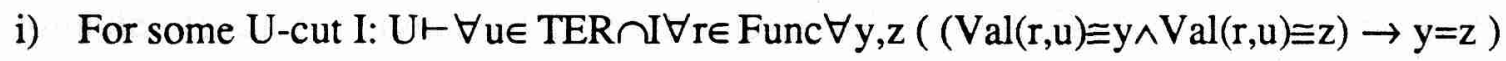

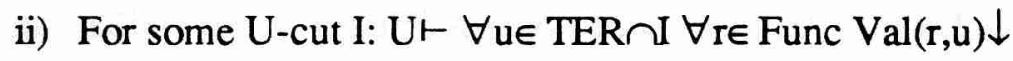

Proof: (i) Let $X:=\{u \in T E R \mid \forall r \in F u n c \forall y, z((\operatorname{Val}(r, u) \cong y \wedge \operatorname{Val}(r, u) \cong z) \rightarrow y=z)\}$. Let $X^{\prime}:=$ $\{u \in X \mid \forall v \leq u v \in X\}$ and suppose $u \in X^{\prime}$. Consider $v:=u+1$. Suppose $v \in T E R, r \in F u n c$, $\operatorname{Val}(r, v) \cong y$ and $\operatorname{Val}(r, v) \cong z$. If $v=\operatorname{Var}(x)$, then $y=z=[r] x$. If $v=\underline{c}$, the $y=z=c$. Suppose $v=A p p(\underline{G}, s, t)$. Let $w$ witness $\operatorname{Val}(r, u) \cong y$, let $w^{\prime}$ witness $\operatorname{Val}(r, u) \cong z$. For some $i, j<L t h(w)-1$ we have $(w)_{i}=<2, r, s, p>,(w)_{j}=<2, r, t, q>, y=G(p, q)$. For some $i^{\prime}, j^{\prime}<L$ th $\left(w^{\prime}\right)-1$ we have $\left(w^{\prime}\right)_{i^{\prime}}=<2, r, s, p^{\prime}>,(w)_{j^{\prime}}=<2, r, t, q^{\prime}>, z=G\left(p^{\prime}, q^{\prime}\right)$. Clearly $r$ and $t$ are in $X^{\prime}$. Moreover $w^{\prime}(i+1)$ witnesses $\operatorname{Val}(r, s) \cong p, w^{\top}(j+1)$ witnesses $\operatorname{Val}(r, s) \cong q$, $w^{\prime}\left(i^{\prime}+1\right)$ witnesses $\operatorname{Val}(r, s) \cong p^{\prime}$, $w^{\prime} \uparrow\left(j^{\prime}+1\right)$ witnesses $\operatorname{Val}(r, s) \cong q^{\prime}$. ergo $p=p^{\prime}, q=q^{\prime}$ and thus $y=z$. We conclude that $X^{\prime}$ is closed under successor. We find I by shortening $\mathrm{X}$ :

(ii) The proof is similar to that of (i).

Let $S N:=\{x \mid \exp (x)$ exists $\}$. Let for $r$ in Func $A[r]$ stand for the result of substituting the numeral of [r]i for $\operatorname{Var}(i)$ in $A$ for all i such that $\operatorname{Var}(i)$ occurs in $A$.

\subsubsection{Fact}

i) $\Omega \vdash \forall x \in S N$ "the formula Sat $_{\mathrm{x}}$ exists", 
Proof: (i) By the trick of Ferrante \& Rackoff. (ii) By carefully formalizing the proof of Tarski's Theorem using 2.4.3. An estimate on the proofs is used to justify the induction. One readily finds that the number of symbols of the proofs can be estimated by $P(x)$ for some standard polynomial $P$. (Here it is most convenient to assume that $\leftrightarrow$ is a defined symbol of the language. If $\leftrightarrow$ is primitive the naive way of proceeding makes the number of symbols of the proofs exponential in $\mathrm{x}$. However by a trick one can circumvent the problem.)

\subsubsection{Fact}

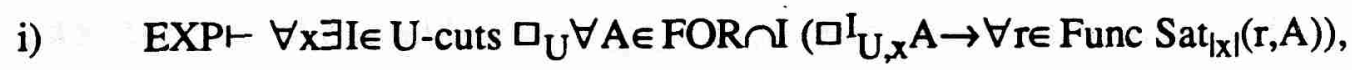

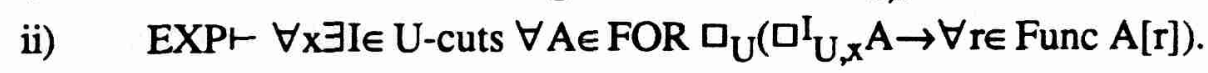

Proof: (ii) follows from (i) by 2.4.4(ii). We sketch the proof of (i). Reason in EXP. Let $\alpha$ be the axiom set of $U . \alpha[x]:=\{A \leq x \mid A \in \alpha\}$. Note that: $A \leq x \rightarrow \rho(A) \leq|A| \leq|x|$. We first show: for all $x: \square_{U} \forall A \in \alpha[x] \forall r \in$ Func $\operatorname{Sat}_{|x|}(r, A)$. By a well known argument: $\square_{U} \forall y \leq x W\{y=z \mid z \leq x\}\left(^{*}\right)$. Note that in the statement of $\left(^{*}\right) \mathrm{y}$ is 'internal' to $\square_{U}$ and $\mathrm{x}$ and the $\mathrm{z}$ are 'external' or 'relatively standard'. (The code of the disjunction involved in the statement of $\left(^{*}\right)$ has size exponential in $x$. The proof of $\left(^{*}\right)$ is by induction on $x$ using an exponential bound of the form $\exp (P(x))$ for a suitable standard polynomial $P$ for the U-proof of $\forall y \leq x W\{y=z \mid z \leq x\}$.) From (*) it is immediate that it is sufficient to show: $\forall A \leq x \square_{U}\left(A \in \alpha[x] \rightarrow \forall r \in\right.$ Func Sat $\left._{|x|}(r, A)\right)$. Since $\alpha$ is $\Delta^{\mathrm{b}}{ }_{1}$ this is equivalent to: $\forall A \in \alpha[x] \square_{U} \forall r \in$ Func Sat $\left.\right|_{|x|}(r, A)$, which is immediate from 2.4.4 (ii).

For the main argument fix $x$. Let:

$X:=\left\{p \mid p\right.$ is an $U, x$-proof such that $\forall r \in$ Func Sat $\left._{|x|}(r, \operatorname{Concl}(p))\right\}$.

Let $X^{\prime}:=\{p \in X \mid \forall q \leq p q \in X\}$. Using the above insight about the axioms of $U$ it is easy to verify that $X^{\prime}$ is closed under successor. (The argument will, of course, vary with the system adopted. If we work in natural deduction the statement of the theorem should be made slightly general to handle proofs from assumptions.) Finally we shorten $X^{\prime}$ to a cut $I$.

Note that 2.4 .5 could be improved by just demanding that the number of steps of $\mathrm{p}$ is in I instead of $p$ itself.

2.4.6 Fact: Suppose that $U$ is finitely axiomatized then:

i) $\Omega \vdash \forall x \exists I \in U$-cuts $\square_{U} \forall A \in F O R \cap I\left(\square_{U, x} A \rightarrow \forall r \in\right.$ Func Sat $\left._{|x|}(r, A)\right)$,

ii) $\Omega \vdash \forall x \exists I \in U$-cuts $\forall A \in$ FOR $\square_{U}\left(\square L_{U, x} A \rightarrow \forall r \in\right.$ Func $\left.A[r]\right)$.

Proof: Apply the forgetful functor to the proof of 2.4.6 and note that the remaining proof does not use EXP. 
2.4.7 Remark: The improvement of 2.4.6 over 2.4.5 works in several other cases, where the theory in question is infinitely axiomatized, but where the set of axioms is very neat. Examples are PA and $\Omega$. We will not prove this fact here. For the case of $\Omega$ one uses the techniques of Verbrugge[89].

Define: $\exp (\mathrm{x}):=2^{\mathrm{x}}$, itexp $(\mathrm{x}, 0):=\mathrm{x}$, itexp $(\mathrm{x}, \mathrm{y}+1) ;=\exp (\mathrm{itexp}(\mathrm{x}, \mathrm{y}))$. Let Tproof stand for: Tableaux-proof (in the sense of Paris \& Wilkie[87]) or for some other suitable notion of cutfree-proof. Let for a proof $p: p(p):=\max \left\{p\left((p)_{i}\right) \mid i<L\right.$ th $\left.(p)\right\}$.

2.4.8 Remark: We would like to apply the cut-elimination theorem in the following form: for some standard $\mathbf{k}, \mathrm{k}^{\prime}$ :

$$
\Omega \vdash \forall p, A, y\left(\left(\operatorname{Proof}_{U}(\mathrm{p}, \mathrm{A}) \wedge i \exp \left(\mathrm{p}, \mathrm{k} . \mathrm{p}(\mathrm{p})+\mathrm{k}^{\prime}\right)=\mathrm{y}\right) \rightarrow \exists \mathrm{q} \leq \mathrm{y} \operatorname{Tproof}_{\mathrm{U}}(\mathrm{p}, \mathrm{A})\right)\left(^{*}\right)
$$

Since however the usual estimate uses as measure depth of logical connectives (say: $v$ ) rather than our depth of quantifierchanges $(\rho)$ we cannot apply that estimate. I am convinced that $(*)$ must be true, but I did not verify this in detail. There is however a quick trick to prove the special case where $U$ is sequential and finitely axiomatized and where $A$ is standard. Suppose $\mathrm{U}$ is sequential and finitely axiomatized and let $\mathrm{A}$ be given.

Reason in $\Omega$. Consider $p$ with $\operatorname{Proof}_{U}(p, A)$. Let $u:=\rho(p)$. Note that $v\left(\operatorname{Sat}_{u}(r, x)\right)=m \cdot u+n$ for certain standard $\mathrm{m}$ and $\mathrm{n}$. We transform $\mathrm{p}$ to $\mathrm{q}$ by replacing $\mathrm{B}$ occurring in $\mathrm{p}$ by $B^{*}:=\operatorname{Sat}_{u}\left(r, \underline{B}^{\top}\right)$, where $r$ is the function assigning $x_{i}$ to $i$ for variables $x_{i}$ occurring in $B$. We add some extra steps using the equivalences of 2.4 .2 to make the steps of $q$ valid. Now $q$ is not yet a $\mathrm{U}$-proof since it starts from translations $\mathrm{C}^{*}$ of $\mathrm{U}$-axioms $\mathrm{C}$. We repair this by adding to $\mathrm{q}$ the (standard) U-proofs of $C^{*}$ guaranteed by 2.4 .4 . Similarly we add after the conclusion $A^{*}$ of $\mathrm{q}$ a standard proof of $\mathrm{A}$ from $\mathrm{A}^{*}$ again as guaranteed by 2.4.4. In this way way obtain a new U-proof of $A$, say s. Now $v(s)=m^{\prime} . u+n^{\prime}$, where $m^{\prime}, n^{\prime}$ are standard and depend only on $\mathrm{U}$ and $\mathrm{A}$. Moreover $|s| \leq \mathrm{P}(|\mathrm{p}|)$, where $\mathrm{P}$ is a suitable standard polynomial only depending on $\mathrm{U}$ and $A$. Now we apply the usual cutelimination theorem to $\mathrm{s}$.

Thus we get: for any A there are standard $k, k^{\prime}$ such that:

$$
\Omega \vdash \forall \mathrm{p}, \mathrm{y}\left(\left(\operatorname{Proof}_{\mathrm{U}}(\mathrm{p}, \mathrm{A}) \wedge \operatorname{itexp}\left(\mathrm{p}, \mathrm{k} \cdot \rho(\mathrm{p})+\mathrm{k}^{\prime}\right)=\mathrm{y}\right) \rightarrow \exists \mathrm{q} \leq \mathrm{y} \operatorname{Tproof}_{\mathrm{U}}(\mathrm{p}, \mathrm{A})\right) .
$$

2.5 Interpretability: For the moment we consider two languages $L_{U}$ and $L_{V}$ that are relational, i.e. $L_{U}$ and $L_{V}$ contain no function-symbols or constants.

Interpretations are in this paper: one dimensional, global, relative interpretations without parameters (for a discussion see Pudlak[83] or Visser[90]). An interpretation $\mathbf{M}$ of $L_{V}$ in $L_{U}$ is given by (i) a function $\mathrm{F}$ from the relation symbols of $L_{V}$ to formulas of the language of $L_{U}$ and (ii) a formula $\delta$ (a) of $L_{U}$ having just a free. The image of a relation symbol has precisely 
$a_{1}, \ldots, a_{n}$ free, where $n$ is the arity of the relation symbol. The image of $=$ need not be $a_{1}=a_{2}$. The function $F$ is canonically extended in the following way: $\left(R\left(b_{1}, \ldots, b_{n}\right)\right)^{M}:=A\left(b_{1}, \ldots, b_{n}\right)$, where $A=F(R)$. (To make substitution of the b's possible we rename bound variables in $A$ if necessary. In fact it would be neater to set apart bound variables for the $F(R)$ and for $\delta$ that do not occur in the original $L_{V}$.) $(.)^{\mathrm{M}}$ commutes with the propositional connectives. $(\forall \mathrm{bB})^{\mathrm{M}}:=$ $\forall \mathrm{b}\left(\delta(\mathrm{b}) \rightarrow \mathrm{B}^{\mathrm{M}}\right)$. Similarly for $\exists$.

We can easily extend (.) ${ }^{\mathrm{M}}$ again to map proofs $\pi$ (from assumptions) in $L_{V}$ to proofs $\pi^{\mathrm{M}}$ from the translated assumptions in $L_{U}$ in the obvious way. As is easily seen for a given interpretation $M$ the lengths of the translated objects are given by a fixed polynomial in the lengths of the originals. The graphs of $\mathrm{B}^{\mathrm{M}}$ (considered as a function in $\mathrm{B}$ and $\mathrm{M}$ ) and of $\pi^{\mathrm{M}}$ (considered as a function in $\pi$ and $M$ ) can be arithmetized by $\Delta_{1}$ b-formulas in such a way that the recursive clauses are verifiable in $\mathrm{I} \Delta_{0}+\Omega_{1}$. Using the polynomial bound on the lengths of the values it is easy to verify that $\mathrm{I} \Delta_{0}+\Omega_{1}$ proves that these functions are total. (This is verified in detail in Kalsbeek[89].)

Of course, the restriction to relational languages is unnecessary. To extend the notion of interpretation we employ certain standard translations from the language with function symbols to an associated relational language and back. The main problem is to see, whether the obvious properties of these translations can be verified in $\mathrm{I} \Delta_{0}+\Omega_{1}$.

Consider theories $\mathrm{U}$ (with language $L_{U}$ ) and $\mathrm{V}$ (with language $L_{V}$ ). What does it mean to say that $\mathrm{V}$ is globally interpretable in $\mathrm{U}$ via $\mathrm{M}$ ? I think the obvious definition is this: for every $B \in \alpha_{V}$ there is a proof in $U$ of $B^{M}$. (I assume in this discussion that we are dealing with sentences, in the case of formulas one should consider: $\left(\delta[B] \rightarrow B^{M}\right)$, where $\delta[B]$ is the conjunction of $\delta(b)$ 's, for all free variables b of B.) Given this definition the next step is to show: if $\mathrm{V}$ is interpretable in $\mathrm{U}$ via $\mathrm{M}$ and if $\mathrm{V}$ proves $\mathrm{C}$, say by $\pi$, then there is a proof $\pi *$ in $\mathrm{U}$ of $\mathrm{C}^{\mathrm{M}}$. Roughly $\pi^{*}$ is $\pi^{\mathrm{M}}$ with proofs of the translated $T^{*}$-axioms plugged in at the relevant places. Now here is a problem: in a theory like $I \Delta_{0}+\Omega_{1}$ we cannot exclude that the proofs of the translated $\mathrm{V}$-axioms are cofinal in the natural numbers. In other words we cannot prove that there is a bound for these proofs. The axiom that would provide such bounds is $\Sigma_{1}$-collection. (So we would get this basic property in $\mathrm{B} \Sigma_{1}+\Omega_{1}$, where $\mathrm{B} \Sigma_{1}:=\mathrm{I} \Delta_{0}+\Sigma_{1}$ - collection.)

We evade the problem by making a definitional move. We change the definition of interpretability in such a way that the basic properties we want are guaranteed even in $\mathrm{I} \Delta_{0}+\Omega_{1}$, but also in such a way that our definition and the usual one collapse in the presence of $\mathrm{B} \Sigma_{1}+\Omega_{1}$.

Define $(\forall x \exists y) * A(x, y)$ by: $\forall u \exists v \forall x<u \exists y<v A(x, y)$. Similarly for more variables. We also write: $(\forall x \in \alpha \exists y \in \beta) * A(x, y)$ for: $\forall u \exists v \forall x<u(x \in \alpha \rightarrow \exists y<v(y \in \beta \wedge A(x, y)))$. 
$\Pi_{2}^{*}:=\left\{(\forall \mathrm{x} \exists \mathrm{y}) * \mathrm{Al} A \in \Delta_{0}\right\}$

Note that if $(\forall x \exists y)^{*} A(x, y)$ and $(\forall y \exists z) * B(y, z)$, then: $(\forall x \exists y, z)^{*}(A(x, y) \wedge B(y, z))$.

Define:

$$
\begin{aligned}
& \mathrm{K}: U \triangleright{ }_{\mathrm{a}} \mathrm{V}: \Leftrightarrow \forall \mathrm{x} \in \alpha_{\mathrm{V}} \operatorname{Prov}_{\mathrm{U}}\left(\mathrm{x}^{\mathrm{K}}\right) . \\
& \mathrm{K}: \mathrm{U} \triangleright \mathrm{V}: \Leftrightarrow\left(\forall \mathrm{x} \in \alpha_{\mathrm{V}} \exists \mathrm{p}\right)^{*} \operatorname{Proof}_{\mathrm{U}}\left(\mathrm{p}, \mathrm{x}^{\mathrm{K}}\right) .
\end{aligned}
$$

Our first notion is axioms interpretability; our second notion is smooth interpretability. Our definitional move is to use smooth interpretability instead of axioms interpretability. In $\mathrm{B} \Sigma_{1}$ the two notions collapse.

Let $U[z]$ be the theory axiomatized by $\alpha_{U}(y) \wedge y \leq z$.

Note that (in $I \Delta_{0}+\Omega_{1}$ ):

$\mathrm{K}: \mathrm{U} \triangleright \mathrm{V}[\mathrm{z}] \Leftrightarrow \exists \mathrm{y} \forall \mathrm{x} \in \alpha_{\mathrm{V}[\mathrm{z}]} \exists \mathrm{p}<\mathrm{yProof} \operatorname{Pr}_{\mathrm{U}}\left(\mathrm{p}, \mathrm{x}^{\mathrm{K}}\right)$, and hence:

$\mathrm{K}: \mathrm{U} \triangleright \mathrm{V} \quad \Leftrightarrow \forall \mathrm{z} \mathrm{K}: \mathrm{U} \triangleright \mathrm{V}[\mathrm{z}]$. Also:

$\mathrm{K}: \mathrm{U} \triangleright \mathrm{V}[\mathrm{z}] \Leftrightarrow \exists \mathrm{y} \exists \mathrm{u} \forall \mathrm{x} \in \alpha_{\mathrm{V}[\mathrm{z}]} \exists \mathrm{p}<\mathrm{uProof} \mathrm{U}_{\mathrm{y}]}\left(\mathrm{p}, \mathrm{x}^{\mathrm{K}}\right)$, and thus:

$\mathrm{K}: \mathrm{U} \triangleright \mathrm{V} \quad \Leftrightarrow \forall \mathrm{z} \exists \mathrm{y} \mathrm{K}: \mathrm{U}[\mathrm{y}] \triangleright \mathrm{V}[\mathrm{z}]$.

We can arrange it so that $\mathrm{K}$ occurs in the arithmetization as a number, so it is possible to quantify over $\mathrm{K}$ in the theory. Define:

$$
\begin{aligned}
& \mathrm{K}: \mathrm{U} \equiv \mathrm{V}: \mathrm{M}: \Leftrightarrow \mathrm{K}: \mathrm{U} \triangleright \mathrm{V} \wedge \mathrm{M}: \mathrm{V} \triangleright \mathrm{U} \\
& \mathrm{U} \triangleright_{\mathrm{glob}} \mathrm{V}: \Leftrightarrow \exists \mathrm{K} \mathrm{K}: \mathrm{U} \triangleright \mathrm{V} \\
& \mathrm{U} \triangleright_{\mathrm{loc}} \mathrm{V}: \Leftrightarrow \forall \mathrm{x} \exists \mathrm{K} \mathrm{K}: \mathrm{U} \triangleright \mathrm{V}[\mathrm{x}] \\
& \mathrm{U} \equiv_{\mathrm{glob}} \mathrm{V}: \Leftrightarrow \mathrm{U}{{ }_{\mathrm{glob}}} \mathrm{V} \wedge \mathrm{V} \triangleright_{\mathrm{glob}} \mathrm{U} \\
& \mathrm{U} \equiv_{\mathrm{loc}} \mathrm{V} \quad: \Leftrightarrow \mathrm{U} \triangleright_{\mathrm{loc}} \mathrm{V} \wedge \mathrm{V} \triangleright_{\mathrm{loc}} \mathrm{U} \\
& \|\mathrm{U}\|_{\mathrm{glob}}:=\left\{\mathrm{Vl} \mathrm{U} \equiv_{\mathrm{glob}} \mathrm{V}\right\} \\
& \|\mathrm{V}\|_{\mathrm{glob}} \leq\|\mathrm{U}\|_{\mathrm{glob}}: \Leftrightarrow \mathrm{U} \triangleright_{\mathrm{glob}} \mathrm{V} \\
& \mathrm{LOC} C_{\mathrm{glob}}(\mathrm{U}):=<\left\{\|\mathrm{V}\|_{\mathrm{glob}} \mid \mathrm{U} \equiv_{\mathrm{loc}} \mathrm{V}\right\}, \leq>
\end{aligned}
$$

Note (in $I \Delta_{0}+\Omega_{1}$ ): if $w<x$ and $K: U \triangleright V[x]$, then $K$ : $U \triangleright V[w]$. So:

$$
\mathrm{U} \triangleright{ }_{\mathrm{loc}} \mathrm{V} \Leftrightarrow(\forall \mathrm{x} \exists \mathrm{K})^{*} \mathrm{~K}: \mathrm{U} \triangleright \mathrm{V}[\mathrm{x}] \text {. }
$$

Similarly: $U \triangleright{ }_{\text {loc }} \mathrm{V} \Leftrightarrow(\forall \mathrm{x} \exists \mathrm{K}, \mathrm{y}) * \forall \mathrm{u} \in \alpha_{\mathrm{V}[\mathrm{x}]} \exists \mathrm{p}<\mathrm{yProof}_{\mathrm{U}}(\mathrm{p}, \mathrm{u} \mathrm{K})$. Thus $\mathrm{U} \triangleright_{\mathrm{loc}} \mathrm{V}$ is modulo provable equivalence in $\Pi_{2}^{*}$. Finally clearly: $\Omega \vdash U \triangleright_{\text {glob }} \mathrm{V} \rightarrow \mathrm{U} \triangleright_{\mathrm{loc}} \mathrm{V}$. 
2.5.1 Pudlák's theorem on cuts: Let $U$ be any sequential theory and let $K$ be an interpretation of a theory $\mathrm{V}$ extending $\mathrm{Q}$ in $\mathrm{U}$. Then there is a $\mathrm{U}$-cut $\mathrm{I}$ and a definable isomorphism $\mathrm{F}$ between I and an 'external cut' of the $\mathrm{K}$-numbers. To spell this out let's call the numbers of the interpretation $\mathrm{NK}^{\mathrm{K}}$, the $\mathrm{K}$-successor relation $\operatorname{Succ}^{\mathrm{K}}, \mathrm{K}$-addition Plus $\mathrm{K}$, etc. The claim is that there is a formula $F(x, y)$ in the language of $U$ (where $|I|$ and $|F|$ are polynomial in $\mid \mathrm{KI})$ such that:

i) Uト $\forall \mathrm{x} \in \mathrm{I} \exists \mathrm{y} \in \mathrm{N}^{\mathrm{K}} \mathrm{F}(\mathrm{x}, \mathrm{y})$.

ii) Uト $\forall \mathrm{x} \in \mathrm{I} \forall \mathrm{y}, \mathrm{z}\left(\left(\mathrm{F}(\mathrm{x}, \mathrm{y}) \rightarrow\left(\mathrm{F}(\mathrm{x}, \mathrm{z}) \leftrightarrow \mathrm{y}=\mathrm{K}_{\mathrm{z}}\right)\right.\right.$.

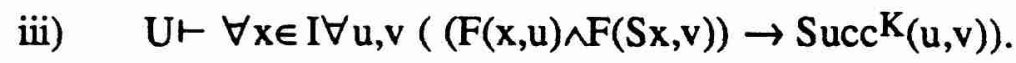

iv) Uト $\forall \mathrm{x}, \mathrm{y} \in \mathrm{I} \forall \mathrm{u}, \mathrm{v}, \mathrm{w}\left((\mathrm{F}(\mathrm{x}, \mathrm{u}) \wedge \mathrm{F}(\mathrm{y}, \mathrm{v}) \wedge \mathrm{F}(\mathrm{x}+\mathrm{y}, \mathrm{w})) \rightarrow \operatorname{Plus}^{\mathrm{K}}(\mathrm{u}, \mathrm{v}, \mathrm{w})\right)$.

v) Uト $\forall \mathrm{x}, \mathrm{y} \in \mathrm{I} \forall \mathrm{u}, \mathrm{v}, \mathrm{w}\left((\mathrm{F}(\mathrm{x}, \mathrm{u}) \wedge \mathrm{F}(\mathrm{y}, \mathrm{v}) \wedge \mathrm{F}(\mathrm{x} \times \mathrm{y}, \mathrm{w})) \rightarrow \operatorname{Times}^{\mathrm{K}}(\mathrm{u}, \mathrm{v}, \mathrm{w})\right)$.

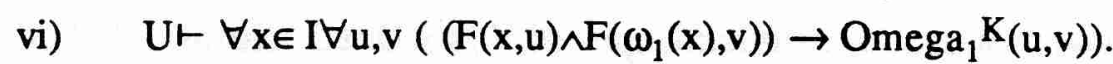

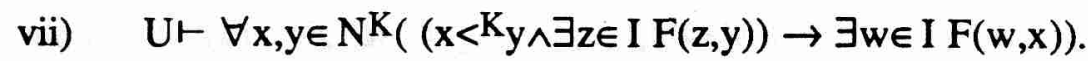

Pudlák's Theorem is verifiable in $\Omega$.

Proof: See Pudlák[85] or Visser[90].

\section{General Facts concerning Local \& Global Interpretability}

3.1 Characterizations of Local Interpretability: We open this section by giving two characterizations of local interpretability. The first is a generalization of the usual Orey-Hájek characterization of global intepretability for essentially reflexive theories, the second one generalizes the 'identification' of global intepretability for essentially reflexive theories with $\Pi_{1}$-conservativity. No characterizations of comparable generality are known for global interpretability: curiously we only have characterizations of global interpretability for classes of theories (viz. essential reflexive and finitely axiomatized) where local and global interpretability coincide!

3.1.1 Definition: $\square_{U^{c} A}: \leftrightarrow \exists I \in U$-cuts $\square_{U}{ }^{I} A$.

3.1.2 Theorem: let $U$ and $V$ be sequential theories, then:

i) $\quad \mathrm{EXP} \vdash \mathrm{U} \triangleright{ }_{\text {loc }} \mathrm{V} \leftrightarrow \forall \mathrm{x}_{\mathrm{U}^{\mathrm{c}}} \mathrm{Con}_{\mathrm{x}}(\mathrm{V})$.

ii) If $\mathrm{V}$ is finitely axiomatized, then:

$\Omega \vdash \mathrm{U}{ }_{\text {glob }} \mathrm{V} \leftrightarrow \forall \mathrm{x} \square_{\mathrm{U}^{\mathrm{c}}}^{\mathrm{C} \mathrm{Con}_{\mathrm{x}}}(\mathrm{V})$

Proof: (i) Reason in EXP. " $\rightarrow$ " By 2.4.6: $\forall x \square_{V}^{c} C^{c o n}(V)$. The desired result is immediate by combining this with Pudlák's theorem on cuts 2.5.1. " $\leftarrow$ " For every $x$ use $\square_{U}^{c} C^{c} n_{x}(V)$ to construct a Henkin-interpretation of $\mathrm{V}[\mathrm{x}]$ (see Visser[90] for details). The proof of (ii) is 
similar.

3.1.3 Theorem: let $U$ and $V$ be sequential theories, then:

i) $\quad \mathrm{EXP} \vdash \mathrm{U} \triangleright{ }_{10 \mathrm{c}} \mathrm{V} \leftrightarrow \forall \mathrm{P} \in \Pi_{1}\left(\square_{\mathrm{V}} \mathrm{cP} \rightarrow \square_{\mathrm{U}} \mathrm{cP}\right)$.

ii) If $\mathrm{V}$ is finitely axiomatized, then:

$\Omega \vdash U{ }_{\text {glob }} \mathrm{V} \leftrightarrow \forall \mathrm{P} \in \Pi_{1}\left(\square_{\mathrm{V}} \mathrm{cP} \rightarrow \square_{\mathrm{U}} \mathrm{cP}\right)$.

Proof: (i) Reason in EXP. " $\rightarrow$ " Immediate by Pudlák's Theorem on Cuts. " $\leftarrow$ " This is a direct consequence of 3.1.2. The proof of (ii) is similar.

\section{$3.2 \mathrm{LOC}_{\mathrm{glob}}(\mathrm{U})$ has a maximum}

3.2.1 Lemma: Let $U$ and $V$ be sequential theories and let $I$ be an $U$-cut. Then there is an $M$

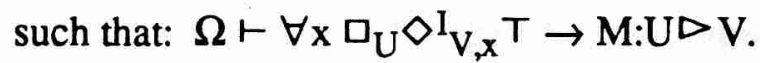

Proof: This is a variant of Feferman's argument. Reason in $\Omega$ : suppose: $\forall \mathbf{x} \square_{U^{\prime}} \diamond \mathrm{I} v, x^{\top}$. Let

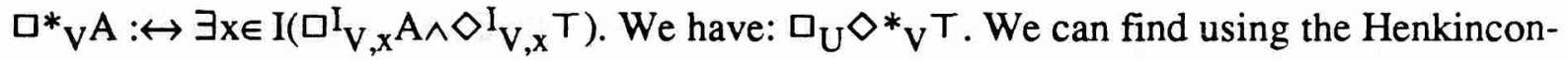
struction an interpretation $M$ based on $\square^{*} V$, such that for all $A \square_{U}\left(\square^{*} V A \rightarrow M(A)\right.$ ) and $\square_{U}\left(M(A) \rightarrow A^{M}\right)$ (see e.g. Visser[90]). Suppose $\square_{\underline{V}} A$, then for some $x \square_{U}\left(\square_{V, x} A \wedge \diamond_{V, x}\right)^{I}$, hence $\square_{U}{ }^{*}{ }_{V} A$. We may conclude $\square_{U} A^{M}$.

Define for sequential $U$ RCon(U): $=\left\{\diamond_{U, n} T \ln \in \omega\right\}$.

3.2.2 Claim: Let sequential theories $\mathrm{U}$ and $\mathrm{V}$ be given. We have:

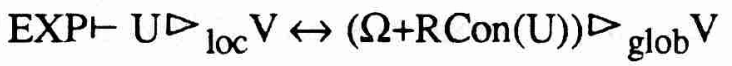

Clearly this tells us (in EXP) that $\| \Omega+R C$ Con $(U) \|_{\text {glob }}$ is the maximum of $L_{\text {glob }}(U)$.

Proof: Reason in EXP. Let $\mathrm{W}:=\Omega+\mathrm{RCon}(\mathrm{U})$.

$" \rightarrow$ " Suppose UD ${ }_{10 \mathrm{C}} \mathrm{V}$. By 3.2.1 it is sufficient to show that: $\forall \mathrm{x} \square_{\mathrm{W}} \diamond_{\mathrm{V}, \mathrm{x}}{ }^{\top}$. As is easily seen this follows in its turn from: $\forall x \exists y \square_{\Omega}\left(\diamond_{U, x}{ }^{\top} \rightarrow \diamond_{V, x}{ }^{\top}\right)$.

Consider $x$. Suppose $K: U \triangleright V[x]$ and find $v$ such that $\forall A \in \alpha_{V[x]} \exists p \leq v \operatorname{Proof}_{U}\left(p, A^{K}\right)$. Clearly (by EXP): $\square_{\Omega} \forall A \in \alpha_{V[x]} \exists p \leq$ vProof $_{U}\left(p, A^{K}\right)$. Let $u$ be such that for any $C \rho\left(C^{K}\right)=p(C)+u$. Take $y:=\max (\exp (|x|+u), v)$, Reason in $\square_{\Omega}$ : Let $q$ be an $V, x-$ proof of $\perp$. It is easy to see that using $\mathrm{K}$ q can be transformed into an $\mathrm{U}, \mathrm{y}$-proof of $\perp$. End of reasoning in $\square_{\Omega}$.

$" \leftarrow "$ It is sufficient to show $U \triangleright_{\text {loc }}(\Omega+R \operatorname{Con}(U))$, which is immediate from 2.4.5.

Note that it is immediate from 3.2.2 and 2.5.1 that $\mathrm{V}$ is in the maximum among the degrees of global interpretability iff for some V-cut I V proves RCon(U)I. 
3.2 is somewhat unsatisfactory because of its dependence on EXP. So it is of some interest to see in how far this defect can be repaired. The next theorem is only a first step in this direction.

3.2.3 Claim: Let sequential theories $U$ and $V$ be given.

i) $\quad \Omega \vdash U \triangleright{ }_{\text {loc }} \mathrm{V} \Rightarrow$ there is an $\mathrm{M} \Omega \vdash \mathrm{M}:(\Omega+\mathrm{RCon}(\mathrm{U})) \triangleright \mathrm{V}$

ii) Suppose $U$ is finitely axiomatized (or $\Omega$ or PA) then: $\Omega \vdash U \triangleright{ }_{10 c}(\Omega+R C o n(U)$ )

iii) Suppose $\mathrm{U}$ is finitely axiomatized (or $\Omega$ or PA) then:

$$
\Omega \vdash \mathrm{U} \triangleright_{\text {loc }} \mathrm{V} \Leftrightarrow \Omega \vdash(\Omega+\mathrm{RCon}(\mathrm{U})) \triangleright_{\text {glob }} \mathrm{V}
$$

Proof: Let $\mathrm{W}:=\Omega+R \operatorname{Con}(\mathrm{U})$.

i) Suppose $\Omega \vdash U \triangleright{ }_{\text {loc }} \mathrm{V}$, then by Parikh's Theorem there are $\mathrm{n}$ and $\mathrm{k}$ and there is a $\Delta_{1}\left(\omega_{1}\right)$ definable function $F$ such that:

$$
\Omega \vdash \forall x \exists K \leq \omega_{1}^{n}(x+\underline{k}) \forall A \in \alpha_{V[x]} \exists p \leq \omega_{1}^{n}(x+\underline{k}) \operatorname{Proof}_{U}\left(p, A^{K}\right) .
$$

Reason in $\Omega$. By 3.2.1 it is sufficient to show that: $\forall \mathbf{x} \square_{\mathrm{W}} \diamond_{\mathrm{V}, \mathrm{x}}{ }^{\top}$. As is easily seen this follows in its turn from: $\forall x \exists y \square_{\Omega}\left(\diamond_{U, y}{ }^{\top} \rightarrow \diamond_{V, x}{ }^{\top}\right)$.

Consider $\mathrm{x}$ and take $\mathrm{y}:=\mathrm{x} \cdot\left|\omega_{1} \mathrm{n}(\mathrm{x}+\underline{\mathrm{k}})\right| \cdot\left(^{*}\right)$ gives:

$$
\square_{\Omega} \exists K \leq \omega_{1} n(x+\underline{k}) \forall A \in \alpha_{V[x]} \exists p \leq \omega_{1} n(x+\underline{k}) P \operatorname{Proof}_{U}\left(p, A^{K}\right) \text {. }
$$

Reason in $\square_{\Omega}$ : consider a $K$ as promised. Evidently $\rho\left(C^{K}\right) \leq \rho(C)+\mid \omega_{1} n(x+\underline{k}) l$. Let $q$ be an $\mathrm{V}, \mathrm{x}$-proof of $\perp$. It is easy to see that using $\mathrm{K} q$ can be transformed into an $\mathrm{U}, \mathrm{y}$-proof of $\perp$. End of reasoning in $\square_{\Omega}$.

Note that we couldn't have chosen $\mathrm{K}$ first and then have moved into $\square_{\Omega}$, since we have -lacking full $\sum$-completeness- no guaruantee that the desired property of $\mathrm{K}$ is preserved going into $\square_{\Omega}$ !

(ii) is immediate from $2 \cdot 4.6$ and 2.4.7. (iii) is immediate from (i) and (ii).

We exhibit a different theory in the maximum of $\mathrm{LOC}_{\mathrm{glob}}(\mathrm{U})$ for finitely axiomatized $\mathrm{U}$ (or for $\mathrm{U}=\Omega$ ).

Define: $\Omega_{\infty}:=\Omega+\left\{\Omega_{n} \mid n \in S N\right\}$. Tcon will mean: Tableaux-consistency. Remember that $\exp (x)=2^{x}, S N=\{x \mid \exp (x) \operatorname{exists}\}$ and $i t \exp (x, 0)=x, \operatorname{itexp}(x, y+1)=\exp (i t e x p(x, y))$.

3.2.4 Claim: Let $U$ be sequential and finitely axiomatized, we have:

$$
\Omega \vdash\left(\Omega_{\infty}+\mathrm{T} \operatorname{con}(\mathrm{U})\right) \equiv_{\mathrm{glob}}(\mathrm{U}+\mathrm{RCon}(\mathrm{U}))
$$

Proof: "ひ" By 3.2.3 it is sufficient to show $\Omega \vdash U \triangleright{ }_{\text {loc }}\left(\Omega_{\infty}+T \operatorname{con}(U)\right)$. Reason in $\Omega$. Since 
$U$ is finitely axiomatized we can find a standard $U$ cut $I_{1}$ such that $U$ proves Tcon(U) on $I_{1}$ (see e.g. Visser[90]). We construct for $y \in S N$ the cuts $I_{y}$ of 2.2 starting from $I_{1}$ such that $U$ proves closure of $\mathrm{I}_{\mathrm{y}}$ under $\omega_{\mathrm{y}}$. Use the estimates sketched in 2.2 .5 to verify that the construction is possible in $\Omega$. Clearly the $\mathrm{I}_{\mathrm{y}}$ interpret $\mathrm{I} \Delta_{0}+\mathrm{T} \operatorname{con}(\mathrm{U})+\Omega_{1}+\ldots+\Omega_{\mathrm{y}}$.

" $\triangleright$ " Reason in $\Omega$. Let $\mathrm{X}_{\mathrm{y}}:=\{$ ulitexp $(\mathrm{u}, \mathrm{y})$ exists $\}$. Note that $\mathrm{X}_{0}=\omega$. Define:

$\mathfrak{I}:=\bigcap\left\{X_{y} l y \in S N\right.$ and $X_{y}$ is a cut $\}$.

It is easy to see that $\mathfrak{I}$ is a $\left(\Omega_{\infty}+T \operatorname{con}(U)\right)$-cut. Let $V:=\Omega_{\infty}+T \operatorname{con}(U)$. We claim that for any $w \in S N: \square_{V}\left(\forall x \in \mathfrak{I}\right.$ itexp $(x, w)$ exists). Fix $w \in S N$. Clearly it is sufficient to show that $X_{w}$ is a V-cut (and hence $\left.\square_{V}\left(\mathfrak{I} \subseteq X_{w}\right)\right)$ and that $\square_{V}\left(\forall x \in X_{w}\right.$ itexp $(x, w)$ exists). We prove both claims simultaneously using 2.2 .3. Remember that $Z$ is $z$-closed if $Z$ is closed under is $\#_{Z}$ (or equivalently: $\mathrm{Z}$ is closed under $\omega_{\mathrm{Z}}$ ), $1 \in \mathrm{Z}$ and $\mathrm{Z}$ is downwards closed under $\leq$. Let's say:

$\mathrm{Z}$ is $w, y$-strong if $\mathrm{y} \leq \mathrm{w}, \mathrm{Z}$ is (w-y)-closed and $\forall \mathrm{x} \in \mathrm{Z}$ itexp( $\mathrm{x}, \mathrm{y})$ exists

So we want to prove that $X_{w}$ is $w+1$,w-strong. From 2.2.3 we see how to construct a proof of " $\mathrm{X}_{\mathrm{y}+1}$ is $\mathrm{w}+1, \mathrm{y}+1$-strong" from " $\mathrm{X}_{\mathrm{y}}$ is $\mathrm{w}+1, \mathrm{y}$-strong". For any $\mathrm{w}$ trivially V proves: $\mathrm{X}_{0}$ is $w+1,0$-strong. The $V$-proof, say $\pi$, we want looks roughly as follows:

$X_{0}$ is $w+1,0$-strong, hence

$\mathrm{X}_{1}$ is $w+1,1$-strong, hence

....

$X_{\mathrm{w}}$ is $\mathrm{w}+1, \mathrm{w}$-strong.

How many symbols does $\pi$ contain? The number of symbols in each of the steps can be estimated by $m .|w|+n$ for standard $m$ and $n$. So the number of symbols in $\pi$ will be smaller than $m^{\prime} .|w| . w+n '$. Since $w \in S N \pi$ will exist in $\Omega$. We prove the existence of $\pi$ by induction on $y \leq w$, showing that there is a proof $\pi_{y}$ of " $x_{y}$ is $w+1$,y-strong" with $\left|\pi_{y}\right| \leq m$ '. $|w| . y+n$ '.

We verify that $\mathfrak{I}: \mathrm{V} \triangleright(\Omega+\mathrm{RCon}(\mathrm{U}))$. Consider any $z$. Note that for standard $k, k^{\prime}$ $\left(k .|z|+k^{\prime}\right) \in S N$. Reason in $\square_{V}$ : suppose for some $y$ in $\mathfrak{I}$ : Proof $f_{U, z}(y, \perp)$. Then there is an $\mathrm{x} \leq \mathrm{itexp}\left(\mathrm{y}, \mathrm{k} \cdot|\mathrm{z}|+\mathrm{k}^{\prime}\right)$ (for some standard $\mathrm{k}$ and $\mathrm{k}^{\prime}$ ) such that $\operatorname{Tproof}_{\mathrm{U}}(\mathrm{x}, \perp$ ) (see 2.4.8). Quod non. Ergo: $\diamond_{\mathrm{U}, \mathrm{w}}{ }^{\mathfrak{I} T}$. It is easy to find suitable bounds on the $\mathrm{V}$-proofs of $\diamond_{\mathrm{U}, \mathrm{w}}{ }^{\mathrm{J}} \mathrm{T}$, so we are done.

\subsubsection{Theorem: $\operatorname{EXP} \vdash \Omega_{\infty} \equiv_{\mathrm{glob}}(\Omega+\mathrm{RCon}(\Omega))$.}

Proof: For some (standard) m: $\square_{\Omega} \forall x$ ((itexp(x,m) exists) $\rightarrow \neg$ Tproof $_{\Omega}(\mathrm{x}, \perp)$ ). Clearly $\mathrm{X}_{\mathrm{m}}$ : $\Omega_{\infty} \triangleright\left(\Omega_{\infty}+\operatorname{Tcon}(\Omega)\right)$ and hence $\Omega_{\infty} \equiv\left(\Omega_{\infty}+T \operatorname{con}(\Omega)\right)$. It is not difficult to see that 3.2 .4 also works for $\Omega$ instead of a finitely axiomatized, sequential $U$.

\subsubsection{Open problem: is it possible that for some $A(\Omega+A) \equiv_{\text {glob }}(\Omega+R \operatorname{Con}(\Omega))$.}

Note: if $\Omega$ is finitely axiomatizable, i.e if for some finitely axiomatized $U$ ID: $\Omega \equiv U: I D$, then the 
answer is: no. So the only reasonable hope is to find the answer yes.

\section{Löb's Theorem}

All the reasoning of this section can be executed in $\Omega$.

4.1 Lemma: Suppose $U$ is finitely axiomatized and $k$ is large compared to the ranks of the axioms of $U$ and to the rank of $A$, then: $\square_{U} A \rightarrow \square_{\Omega} \square_{U, k} A$.

Proof: Suppose $\square_{U} A$. We construct an interpretation $M$ with $M:\left(\Omega+\diamond_{U, k} \neg A\right) \triangleright(U+\neg A)$. It follows that: $M:\left(\Omega+\diamond_{U, k} \neg A\right) \triangleright \perp$, hence $\square_{\Omega} \square_{U, k} A$.

\subsection{A generalization of Löb's Theorem: Let $U$ be finitely axiomatized. Let $N: U \triangleright V$} and $\mathrm{M}: \mathrm{V} D \mathrm{~W}, \mathrm{~K}=\mathrm{MoN}$. Let $\mathrm{k}$ be large compared to the degrees of $\mathrm{K}, \mathrm{A}$ and the axioms of $\mathrm{U}$. Suppose $\square_{V}\left(\square^{M_{U, k}} A^{N} \rightarrow A\right)$. Then $\square_{V} A$.

Proof: By the Gödel Fixed Point Theorem there is an $m$ and a $B$ such that $\square_{Q, m}\left(B \leftrightarrow\left(\square^{M}{ }_{U, k} B^{N} \rightarrow A\right)\right)$. Note that $m$ depends only on $\rho(A), \rho(M)$ and on the $\rho$ of the arithmetization of the graph of the $\lambda x . x^{N}$. Moreover note that these $\rho$ 's do not depend on $k$ even if $\mathrm{B}$ does depend on $\mathrm{k}$. Let $\mathrm{p}$ be the $\mathrm{U}$-proof of $\mathrm{Q}^{\mathrm{K}}$. Pick $\mathrm{k}$ large compared to $\rho(\mathrm{p}), \mathrm{m}$, $\rho(K)$ and the ranks of the axioms of $U$.

Clearly $\square_{W}\left(\square_{U, k} B^{N} \rightarrow \square_{U, k}\left(\square^{M}{ }_{U, k} B^{N} \rightarrow A\right){ }^{N}\right)$, i.e. $\square_{W}\left(\square_{U, k} B^{N} \rightarrow \square_{U, k}\left(\square^{K} K_{U, k} B^{N} \rightarrow A^{N}\right)\right)$. Also: $\square_{W}\left(\square_{U, k} B^{N} \rightarrow \square_{Q, m} \square_{U, k} B^{N}\right)$. Moreover: $\square_{W} \square_{U, k} Q^{K}$. We find:

$\square_{W}\left(\square_{U, k} B^{N} \rightarrow \square_{U, k}\left(\square_{U, k} B^{N}\right){ }^{K}\right)$.

Hence: $\square_{W}\left(\square_{U, k} B^{N} \rightarrow \square_{U, k} A^{N}\right)$ and thus $\square_{V}\left(\square^{M_{U, k}} B^{N} \rightarrow \square M_{U, k} A^{N}\right)$. From our assumption we get: $\square_{V}\left(\square^{M}{ }_{U, k} B^{N} \rightarrow A\right)$. We may conclude $\square_{V} B$. Hence $\square_{U^{B}}{ }^{N}$ and thus $\square_{V} \square^{M}{ }_{U, k} B^{N}$ and so $\square_{V} A$.

4.3 Definition: A theory $U$ is nearly finite if (i) there is a finitely axiomatized $X$ and there is an X-cut I such that $\mathrm{D}: U \equiv X: I$. (ii) (i) is verifiable in $\Omega$. Note that $\Omega$ is nearly finite.

4.4 Corollary: Let $U$ be nearly finite. Say $X$ is our finitely axiomatized theory and

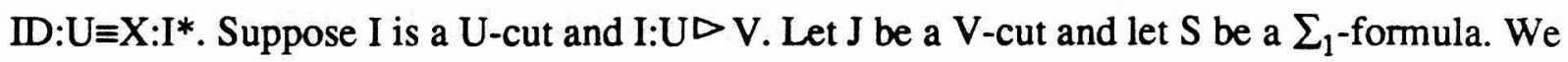
can find $k$ (large compared to the ranks of $I, J, I^{*}, S$ and the axioms of $X$ ), such that:

$$
\square_{\mathrm{V}}\left(\square^{\mathrm{J}} \mathrm{U}, \mathrm{K} \mathrm{S} \rightarrow \mathrm{S}\right) \rightarrow \square_{\mathrm{V}} \mathrm{S} \text {. }
$$

Proof: Let $\mathrm{J}^{*}:=\mathrm{I}^{*} \mathrm{I}$. Note that $\mathrm{J}^{*}: \mathrm{X} \triangleright \mathrm{V}, \mathrm{J}: \mathrm{V} \triangleright \Omega$. Let $\mathrm{K}:=\mathrm{J}_{0} \mathrm{~J}^{*}$. Choose $\mathrm{k}$ large compared to the degrees of complexity of $S$, the axioms of $X$ and $K$. Suppose $\square_{V}\left(\square^{J} U, k \rightarrow S\right)$. Reason in $\mathrm{V}$ : 


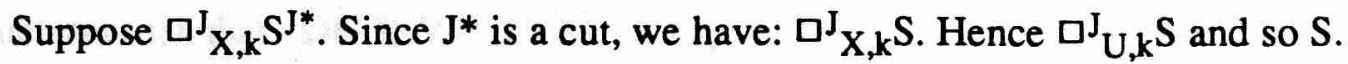
So outside of $\mathrm{V}$, we find: $\square_{\mathrm{V}}\left(\square^{\mathrm{J}} \mathrm{X}, \mathrm{k} \mathrm{S}^{\mathrm{J}} \rightarrow S\right)$. Apply 4.2 to get $\square_{\mathrm{V}} S$.

4.5 Corollary: Let $U$ be consistent, sequential and nearly finite, then

i) $\Omega+R C o n(U)$ is not globally interpretable in $U$,

ii) $\quad \Omega_{\infty}+$ Tabcon(U) is not globally interpretable in $U$.

Moreover:

iii) $\Omega_{\infty}$ is not globally interpretable in $\Omega$.

Proof: i) Suppose $U$ is nearly finite and $\Omega+R C o n(U)$ is globally interpretable in $U$. Then by Pudlák's theorem on cuts 2.5 .1 and the downwards persistence of $\Pi_{1}$-sentences: $\Omega+R C o n(U)$ is interpretable in $U$ on a cut. But then 4.4 implies that $U$ is inconsistent. (ii) follows from (i) by 3.4.2. (iii) follows by 3.2.5.

4.5(i) is due to Pudlák using essentially the same methods. (iii) is due to Paris \& Wilkie by a quite different argument. Note that 4.5 tells us that for nearly finite $\mathrm{U} \mathrm{LOC}_{\mathrm{glob}}(\mathrm{U})$ has at least two elements.

4.6 Discussion: Note that by minimal modifications of the proof of 4.2 we get:

4.6.1 Fact: Let $N: U \triangleright V$ and $M: V \triangleright W, K=M \circ N$. Suppose $\square_{V}\left(\square^{M} A^{N} \rightarrow A\right)$. Then $\square_{V} A$.

The easiness of the adaptation of the usual proof of Löb's Theorem may well give the impression that any generalization along these lines will work. However this is not so. Note that 4.2 and 4.6.1 satisfy a kind of dimension analysis: even if the languages of the theories considered differ the sentence $\mathrm{A}$ is always considered in the right language. 4.4 violates the dimension analysis, but this is explained by the fact that only sentences of a special class are considered and the fact that a very specific property of these sentences is used.

We give two 'anti-Löb' (or: 'fake reflection') examples. First the reader may amuse him/herself by proving the following:

there is a GB-cut I such that: GB $\vdash\left(\square_{G B} \neg S U P E X P \rightarrow \neg S U P E X P\right)^{I}$

The results of the next section imply:

there is a GB-cut I such that: GBम $\square_{G B} \square_{G B} I_{\perp} \rightarrow \square_{G B} \perp$.

Note that both our examples violate 'dimension analysis'.

\section{$5 \quad$ Tunneling $\Sigma$-formulas through}

5.1 Tunneling Theorem: Let $\mathrm{U}$ be finitely axiomatized. Suppose for some $\mathrm{U}$-cut $\mathrm{I}_{0}$ $\mathrm{I}_{0}: \mathrm{U} \triangleright \mathrm{V}$. Let $\mathrm{K}: \mathrm{V} \triangleright \mathrm{U}$ and let $\mathrm{S}$ be any $\Sigma$-formula. Then there is a $\mathrm{U}$-cut J (without further 
parameters) such that: $\Omega \vdash \mathrm{K}: \mathrm{V} \triangleright\left(\mathrm{U}+\mathrm{S}^{\mathrm{J}}\right) \rightarrow \square_{\mathrm{V}} \mathrm{S}$.

Proof: Let I be a V-cut isomorphic with an initial segment of the K-numbers. Say the K-image of $\mathrm{I}$ is $\mathrm{I}^{*}$. Choose $\mathrm{k}$ large compared to the ranks of $\mathrm{I}$ and $\mathrm{S}$; choose $\mathrm{J}$ such that we have reflection in $\mathrm{U}$ for $\square_{\mathrm{U}, \mathrm{k}}^{\mathrm{J}}$ for formulas of sufficiently large rank. Let $\mathrm{R}$ be such that:

$$
\Omega \vdash R \leftrightarrow S \leq \square_{U, k} R .
$$

Reason in $\Omega$ : suppose $\mathrm{K}: \mathrm{V} \triangleright\left(\mathrm{U}+\mathrm{S}^{\mathrm{J}}\right)$. Reason inside $\square_{\mathrm{V}}$ : in $K$ we have $\mathrm{S}^{\mathrm{J}}$. Thus: $\square_{\mathrm{U}, \mathrm{k}} \mathrm{R}<\mathrm{S}$ or $S \leq \square_{U, k} R$. In the first case we find $\square^{J}{ }_{U, k} R$ (because $S^{J}$ ) and hence $R$. But this contradicts $\square_{U, k} R<S$. So we find $S \leq \square_{U, k} R$, i.e. $R$. Go outside of $K$.

Suppose $\square^{I_{U, k}} R$. Then in $K$ : $\square^{I^{*}}{ }_{U, k} R$ and thus $\mathrm{R}^{\mathrm{I}^{*}}$. $\mathrm{R}^{\mathrm{I}^{*}}$. Hence outside $\mathrm{K}$ we have: $\mathrm{R}^{\mathrm{I}}$. Leave the $\square_{\mathrm{V}}$.

Ergo $\square_{V}\left(\square_{U, k} R \rightarrow R\right)$ and hence because $k$ is large compared to $I$ and $S: \square_{V} R$, so $\square_{V} S$. $\square$

\subsection{Corollary: 5.1 also holds for U nearly finite.}

Proof: Trivial.

We write $\Delta$ for tableaux-provability.

5.3 Corollary: Let $\mathrm{U}$ be finitely axiomatized. Let $\mathrm{S}$ be $\Sigma_{1}$. Then there is a U-cut J such that:

i) $\quad \Omega \vdash \square_{U} S^{J} \leftrightarrow \square_{\Omega+T c o n}(U) S$.

ii) $\quad \operatorname{EXP} \vdash \square_{U} S^{J} \leftrightarrow \Delta_{\operatorname{EXP}}(\mathrm{T} c o n(U) \rightarrow S)$.

iii) $\quad$ SUPEXPト $\square_{U} S^{J} \leftrightarrow(\operatorname{Con}(U) \rightarrow S)$.

Proof: (i) First note that $\Omega+T \operatorname{con}(U)$ is interpretable in $U$ via a cut. Let $K:(\Omega+T \operatorname{con}(U)) \triangleright U$. Pick J such that:

$$
\Omega \vdash \mathrm{K}:(\Omega+\mathrm{T} \operatorname{con}(\mathrm{U})) \triangleright\left(\mathrm{U}+\mathrm{S}^{\mathrm{J}}\right) \rightarrow \square_{\Omega+\mathrm{T} c o n}(\mathrm{U}) \mathrm{S} .
$$

Then clearly: $\Omega \vdash \square_{U} S^{J} \rightarrow \square_{\Omega+T c o n(U)} S$. Evidently we may choose J so small that $\Omega \vdash$ $\mathrm{J}: U \triangleright(\Omega+\mathrm{Tcon}(\mathrm{U}))$, hence: $\Omega \vdash \square_{\mathrm{U}} S^{\mathrm{J}} \leftrightarrow \square_{\Omega+\mathrm{Tcon}(\mathrm{U})} S$.

(ii) and (iii) are immediate from (i) using the results of Visser[90] and the fact that $T$ con(U) $\rightarrow S$ is in $\Sigma_{1}$.

5.4 Corollary: Let $U$ be nearly finite. Then there is a U-cut $J$ such that:

i) $\Omega \vdash \square_{U} \square_{U} \mathrm{~A} \leftrightarrow \square_{\Omega} \square_{U} A$.

ii) SUPEXPト $\square_{U} \square_{U}^{J} A \leftrightarrow \square_{U} A$. 
Proof: (i) Let $\mathrm{X}$ witness the nearly finiteness of $\mathrm{U}$. Inspecting the proof of 5.3 we find for any $\Sigma_{1}$-sentence a U-cut J such that $\Omega \vdash \square_{U} S^{J} \leftrightarrow \square_{\Omega+T}$ con(X) $S$. Taking $S:=\square_{U} A$ and noting that $\Omega \vdash \square_{\Omega+T \text { Tincon }(X)} \square_{U} A$ we get the desired result. (ii) is immediate from (i).

Note that if $U$ extends SUPEXP, we find (taking $A:=\perp$ ): $U \vdash \square_{U} \square_{U} \perp \leftrightarrow \square_{U} \perp$. Remember

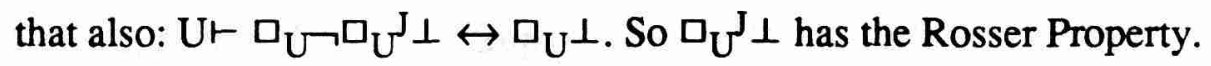

5.5 Corollary: Let $U$ be nearly finite. Let $I$ be a U-cut. Then there is a U-cut $J$ such that: $\Omega \vdash \square_{U}\left(\square_{U}^{I} \perp \rightarrow \square_{U}{ }^{\perp}\right) \leftrightarrow \square_{\Omega} \square_{U} \perp$.

Proof: Reason in $\Omega$. Let $X$ witness the nearly finiteness of $U$. Let $M: U \triangleright\left(U+\square_{U} \perp \perp\right)$ and $\mathrm{P}: \Omega+\mathrm{T} \operatorname{con}(\mathrm{X}) \triangleright \mathrm{U}$. Take $\mathrm{K}:=\mathrm{PoM}$. Let $\mathrm{J}$ be given by 5.1 with $\Omega+\mathrm{T} \operatorname{con}(\mathrm{X})$ in the role of $\mathrm{U}$ and $\square_{\Omega} \perp$ in the role of S. Suppose $\square_{\Omega}\left(\square_{\Omega} I_{\perp} \rightarrow \square_{\Omega}{ }^{J} \perp\right)$. We have:

$$
\mathrm{K}:(\Omega+\mathrm{T} \operatorname{con}(\mathrm{X})) \triangleright\left(\mathrm{U}+\square_{\mathrm{U}} \mathrm{J}^{\perp}\right)
$$

and hence $\square_{\Omega+T} \operatorname{con}(X)^{\square} U^{\perp}$. By the usual reasoning: $\square_{\Omega+T \operatorname{con}(X)} \square_{U} \perp$.

5.6 Corollary: Let J be an $\Omega$-cut such that $\Omega \vdash \forall x \in J 2 x \downarrow$. Then:

$$
\Omega \vdash \square_{\Omega}\left(\square_{\Omega}^{\perp} \rightarrow \square_{\Omega} J^{\perp}\right) \leftrightarrow \square_{\Omega} \square_{\Omega} \perp
$$

Proof: 5.5 guarantees us an $\Omega$-cut J* with $\Omega \vdash \square_{\Omega}\left(\square_{\Omega} \perp \rightarrow \square_{\Omega}{ }^{*} \perp\right) \leftrightarrow \square_{\Omega} \square_{\Omega} \perp$. Inspection of the proof shows that any J* such that for some sufficiently large $\mathrm{k} \Omega \vdash \forall \mathrm{x} \in \mathrm{J} *$ itexp $(\mathrm{x}, \underline{\mathrm{k}}) \downarrow$, will do. (This uses the fact that for any $m$ there is a $k$ such that:

$$
\Omega \vdash \forall x\left(\text { itexp }(x, \underline{k}) \downarrow \rightarrow \neg \operatorname{Proof}_{\Omega, \mathrm{m}}(\mathrm{x}, \perp)\right. \text {.) }
$$

Let $\mathrm{J}$ be an $\Omega$-cut such that $\Omega \vdash \forall x \in J 2^{x} \downarrow$. Define J[0]:=ID, J[n+1]:=J[n] J. Clearly $\Omega \vdash$ $\forall \mathrm{x} \in \mathrm{J}[\mathrm{k}]$ itexp $(\mathrm{x}, \mathrm{k}) \downarrow$. Also:

$$
\begin{aligned}
\Omega \vdash \square_{\Omega}\left(\square^{\mathrm{J}[0]} \Omega^{\perp \rightarrow \square_{\Omega}} \Omega^{\mathrm{J}[1] \perp)}\right. & \rightarrow \square_{\Omega}\left(\square^{\mathrm{J}[1]} \Omega^{\perp} \rightarrow \square_{\Omega}{ }^{\mathrm{J}[2] \perp)}\right. \\
& \rightarrow \square_{\Omega}\left(\square^{\mathrm{J}[2]} \Omega^{\perp} \rightarrow \square_{\left.\Omega^{\mathrm{J}}[3] \perp\right)}\right. \\
& \cdots \\
& \rightarrow \square_{\Omega}\left(\square^{\mathrm{J}[\mathrm{k}-1]} \Omega_{\Omega} \perp \rightarrow \square_{\left.\Omega^{\mathrm{J}}[\mathrm{k}] \perp\right)}\right.
\end{aligned}
$$

Hence $\Omega \vdash \square_{\Omega}\left(\square_{\Omega} \perp \rightarrow \square_{\Omega}{ }^{J} \perp\right) \rightarrow \square_{\Omega}\left(\square_{\Omega} \perp \rightarrow \square_{\Omega} J[k] \perp\right)$, so by our earlier remarks the desired result follows.

In our previous theorems the cut chosen was always dependent on $U$ and on $S$. As a last point we show that the dependence on $S$ can be eliminated.

5.7 Uniform Tunneling Theorem: Let $U$ be finitely axiomatized. Suppose for some $\mathrm{U}$-cut $\mathrm{I}_{0} \mathrm{I}_{0}: \mathrm{U} \triangleright \mathrm{V}$. Let $\mathrm{K}: \mathrm{V} \triangleright \mathrm{U}$. Then there is a $\mathrm{U}$-cut $\mathrm{J}$ (without further parameters) such that $\Omega \vdash \forall S \in \Sigma_{1} K: V \triangleright\left(U+S^{J}\right) \rightarrow \square_{V} S$. 
Proof: Reason in $\Omega$. Let True be the usual $\Sigma_{1}$ truth-predicate for $\Sigma_{1}$-sentences. We have for any $\Sigma_{1}$-formula $S$ (applying the conventions for formulas inside the $\square$ also to True):

$\square_{\Omega}$ (True $\left.(S) \rightarrow S\right)$,

for a fixed standard cut $I^{*}: \square_{\Omega}\left(S^{*} \rightarrow \operatorname{True}(S)\right)$.

Let $\mathrm{J}^{*}$ be the cut provided by the Tunneling Theorem for the formula True $(\mathbf{x})$. Take J:=I*oJ*.

Consider any $S$ in $\Sigma_{1}$. Suppose $K: V \triangleright\left(U+S^{J}\right)$. Then $K: V \triangleright\left(U+\left(S^{I^{*}}\right)^{J^{*}}\right)$. Ergo $\mathrm{K}: \mathrm{V} \triangleright\left(\mathrm{U}+\mathrm{True}(\mathrm{S})^{\mathrm{J}}\right)$. Hence by the Tunneling Theorem $\square_{\mathrm{V}} \mathrm{True}(\mathrm{S})$, so $\square_{\mathrm{V}} S$.

\section{Intermediate Degree}

We show that if $U$ is consistent, sequential and finitely axiomatized, then $\operatorname{LOC}_{\text {glob }}(U)$ has at least three elements. All results in this section are in $\Omega$. $\square:=\square_{U}$, etc.

Suppose $U$ is finitely axiomatized. $U_{\text {inc }}:=U+\left\{C u t(A) \rightarrow \square A \perp \mid A \in F O R_{L}, F V(A)=\{x\}\right\}$ is locally interpretable in $\mathrm{U}$. If $\Omega \nvdash \square \perp$, then $\mathrm{U}_{\text {inc }}$ is not globally interpretable in $\mathrm{U}$. Moreover if $\mathrm{U}$ is consistent, $\mathrm{W}:=\mathrm{U}+\mathrm{RCon}(\mathrm{U})$ is not globally interpretable in $\mathrm{U}_{\mathrm{inc}}$.

Proof: Let $\mathrm{Ct}(\mathrm{A}):=\{\mathrm{x} \mid \mathrm{Cut}(\mathrm{A}) \rightarrow \mathrm{A}(\mathrm{x})\}$. Note $\mathrm{U} \vdash \mathrm{Cut}(\mathrm{A}) \rightarrow \mathrm{Ct}(\mathrm{A})=\mathrm{A}, \mathrm{U} \vdash \mathrm{Cut}(\mathrm{Ct}(\mathrm{A}))$ and $\mathrm{U}+\square \perp \vdash(\mathrm{Cut}(\mathrm{A}) \rightarrow \square \mathrm{A} \perp) \leftrightarrow \square \mathrm{Ct}(\mathrm{A}) \perp$.

To show that $U_{\text {inc }}$ is locally interpretable, consider $A_{1}, \ldots, A_{m}$ in $F O R_{L}$ with $F V\left(A_{j}\right)=\{x\}$. Let $\mathrm{J}:=\bigcap\left\{\mathrm{Ct}\left(\mathrm{A}_{\mathrm{i}}\right) \mid 1 \leq \mathrm{i} \leq \mathrm{m}\right\}$. We have $U \triangleright\left(U+\square^{\mathrm{J}} \perp\right)$ and hence $U \triangleright\left(U+\left\{\operatorname{Cut}\left(\mathrm{A}_{\mathrm{i}}\right) \rightarrow \square \mathrm{A}_{\mathrm{i}} \perp \mid 1 \leq \mathrm{i} \leq \mathrm{m}\right\}\right)$.

Suppose $U_{\text {inc }}$ is globally interpretable in $U$, say by $K_{0}$. Let $M:(\Omega+T \operatorname{con}(U)) \triangleright U$ and $\mathrm{K}:=\mathrm{MoK}_{0}$. Let $\mathrm{J}$ be the cut of our theorem. Clearly: $\Omega+\mathrm{T} \operatorname{con}(\mathrm{U}) \vdash(\operatorname{Cut}(\mathrm{J}))^{\mathrm{K}}$ and $\Omega+\mathrm{Tcon}(\mathrm{U}) \vdash$ $\left(\operatorname{Cut}(\mathrm{J}) \rightarrow \square^{\mathrm{J}} \perp\right)^{\mathrm{K}}$, ergo $\Omega+\mathrm{T} \operatorname{con}(\mathrm{U}) \vdash \square^{\mathrm{JoK}} \perp$. The theorem gives: $\Omega+\mathrm{Tcon}(\mathrm{U}) \vdash \square \perp$ and hence $\Omega \vdash \square \perp$.

Suppose $W$ is globally interpretable in $U_{\text {inc }}$ then there is a fixed $U_{\text {inc }}$-cut $I$ such that for all $n$ : $\mathrm{U}_{\text {inc }} \vdash \operatorname{Con}_{n}{ }_{n}(U)$. Let $m$ be large compared to $I$. We have for some cut $J: U+\square^{J} \perp \vdash C{ }^{\prime}{ }_{m}(U)$.

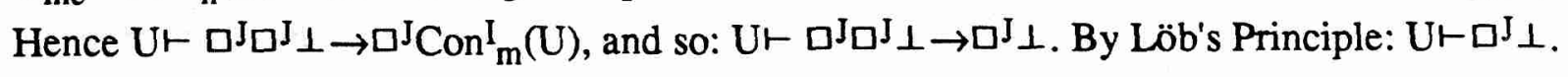
We may conclude $\mathrm{U} \vdash \mathrm{Con}_{\mathrm{m}}^{\mathrm{I}}(\mathrm{U})$. Hence $\mathrm{U}$ is inconsistent.

It is easily seen that our result also works for nearly finite theories (like $\Omega$ ). I end with the obvious conjecture:

6.1 Conjecture: Suppose $U$ is sequential and nearly finite. Then there are infinitely many incomparable elements in $\mathrm{LOC}_{\text {glob }}(\mathrm{U})$. 


\section{References}

Buss, S., 1985, Bounded Arithmetic, Thesis, Princeton University, Princeton. Reprinted: 1986, Bibliopolis, Napoli.

Feferman, S., 1960, Arithmetization of metamathematics in a general setting, Fund. Math. 49, 33-92.

Ferrante, J. \& Rackoff, C.W., 1979, The Computational Complexity of Logical Theories, Springer Lecture Notes 718, Springer, New York.

Gaifman, H. \& Dimitracopoulos, C., 1982, Fragments of Peano's Arithmetic and the MRDP theorem, in: Logic and Algorithmic, Monography 30 de l'Enseignement Mathematique, Genève, 187-206.

Kalsbeek, M.B., 1988, An Orey Sentence for Predicative Arithmetic, ITLI Prepublication Series X-8-01.

Krajícek, J., 1987, A note on proofs of falsehood, Archiv für Mathematik und Grundlagen der Mathematik 26, 169-176.

Parikh, R., 1971, Existence and feasibility in arithmetic, JSL 36, 494-508.

Paris, J.B., Dimitracopoulos, C., 1983, A note on the undefinability of cuts, JSL 48, 564-569.

Paris, J., Wilkie, A., 1987, On the scheme of induction for bounded arithmetic formulas, Annals for Pure and Applied Logic 35, 261-302.

Pudlák, P., 1983, Some prime elements in the lattice of interpretability types, Transactions of the AMS 280, 255-275.

Pudlák, P., 1985, Cuts, consistency statements and interpretability, JSL 50, 423-441.

Pudlák, P., 1986, On the length of proofs of finitistic consistency statements in finitistic theories, in: Paris, J.B. \&al, eds., Logic Colloquium '84, North Holland, 165-196.

Smorynski, C., 1985, Self-Reference and Modal Logic, Springer Verlag.

Takeuti, G., 1988, Bounded arithmetic and truth definition, Annals of Pure \& Applied Logic 36, 75-104.

Verbrugge, R., 1989, $\Sigma$-completeness and Bounded Arithmetic, ITLI Prepublication Series, ML-89-05, University of Amsterdam.

Visser, A, 1989, The Formalization of Interpretability, Logic Group Preprint Series $\mathrm{nr} 47$, Dept. of Philosophy, University of Utrecht, Heidelberglaan 2, 3584CS Utrecht. To appear in Studia Logica.

Visser, A, 1990, Interpretability Logic, in Petkov, P.P. (ed.), 1990, Mathematical Logic, Plenum Press, New York, 175-208. 


\section{Logic Group Preprint Series \\ Department of Philosophy, University of Utrecht \\ Heidelberglaan 2, 3584 CS Utrecht \\ The Netherlands}

1 C.P.J. Koymans, J.L.M. Vrancken, Extending Process Algebra with the empty process, September 1985

2 J.A. Bergstra, A process creation mechanism in Process Algebra, September 1985

3 J.A. Bergstra, Put and get, primitives for synchronous unreliable message passing, October 1985

4 A. Visser, Evaluation, provably deductive equivalence in Heyting's arithmetic of substitution instances of propositional formulas, November 1985

5 G.R. Renardel de Lavalette, Interpolation in a fragment of intuitionistic propositional logic, January 1986

6 C.P.J. Koymans, J.C. Mulder, A modular approach to protocol verification using Process Algebra, April 1986

7 D. van Dalen, F.J. de Vries, Intuitionistic free abelian groups, April 1986

8 F. Voorbraak, A simplification of the completeness proofs for Guaspari and Solovay's $R$, May 1986

9 H.B.M. Jonkers, C.P.J. Koymans \& G.R. Renardel de Lavalette, A semantic framework for the COLDfamily of languages, May 1986

10 G.R. Renardel de Lavalette, Strictheidsanalyse, May 1986

11 A. Visser, Kunnen wij elke machine verslaan? Beschouwingen rondom Lucas' argument, July 1986

12 E.C.W. Krabbe, Naess's dichotomy of tenability and relevance, June 1986

13 H. van Ditmarsch, Abstractie in wiskunde, expertsystemen en argumentatie, Augustus 1986

14 A. Visser, Peano's Smart Children, a provability logical study of systems with built-in consistency, October 1986

15 G.R. Renardel de Lavalette, Interpolation in natural fragments of intuitionistic propositional logic, October 1986

16 J.A. Bergstra, Module Algebra for relational specifications, November 1986

17 F.P.J.M. Voorbraak, Tensed Intuitionistic Logic, January 1987

18 J.A. Bergstra, J. Tiuryn, Process Algebra semantics for queues, January 1987

19 F.J. de Vries, A functional program for the fast Fourier transform, March 1987

20 A. Visser, $A$ course in bimodal provability logic, May 1987

21 F.P.J.M. Voorbraak, The logic of actual obligation, an alternative approach to deontic logic, May 1987

22 E.C.W. Krabbe, Creative reasoning in formal discussion, June 1987

23 F.J. de Vries, A functional program for Gaussian elimination, September 1987

24 G.R. Renardel de Lavalette, Interpolation in fragments of intuitionistic propositional logic, October 1987 (revised version of no. 15)

25 F.J. de Vries, Applications of constructive logic to sheaf constructions in toposes, October 1987

26 F.P.J.M. Voorbraak, Redeneren met onzekerheid in expertsystemen, November 1987

27 P.H. Rodenburg, D.J. Hoekzema, Specification of the fast Fourier transform algorithm as a term rewriting system, December 1987

28 D. van Dalen, The war of the frogs and the mice, or the crisis of the Mathematische Annalen, December 1987

29 A. Visser, Preliminary Notes on Interpretability Logic, January 1988

30 D.J. Hoekzema, P.H. Rodenburg, Gauß elimination as a term rewriting system, January 1988

31 C. Smoryński, Hilbert's Programme, January 1988

32 G.R. Renardel de Lavalette, Modularisation, Parameterisation, Interpolation, January 1988

33 G.R. Renardel de Lavalette, Strictness analysis for POLYREC, a language with polymorphic and recursive types, March 1988

34 A. Visser, A Descending Hierarchy of Reflection Principles, April 1988

35 F.P.J.M. Voorbraak, A computationally efficient approximation of Dempster-Shafer theory, April 1988

36 C. Smoryniski, Arithmetic Analogues of McAloon's Unique Rosser Sentences, April 1988 
37 P.H. Rodenburg, F.J. van der Linden, Manufacturing a cartesian closed category with exactly two objects, May 1988

38 P.H. Rodenburg, J.L.M.Vrancken, Parallel object-oriented term rewriting : The Booleans, July 1988

39 D. de Jongh, L. Hendriks, G.R. Renardel de Lavalette, Computations in fragments of intuitionistic propositional logic, July 1988

40 A. Visser, Interpretability Logic, September 1988

41 M. Doorman, The existence property in the presence of function symbols, October 1988

42 F. Voorbraak, On the justification of Dempster's rule of combination, December 1988

43 A. Visser, An inside view of EXP, or: The closed fragment of the provability logic of $I \Delta 0+\Omega_{1}$. February 1989

44 D.H.J. de Jongh \& A. Visser, Explicit Fixed Points in Interpretability Logic, March 1989

45 S. van Denneheuvel \& G.R. Renardel de Lavalette, Normalisation of database expressions involving calculations, March 1989

46 M.F.J. Drossaers, A Perceptron Network Theorem Prover for the Propositional Calculus, July 1989

47 A. Visser, The Formalization of Interpretability, August 1989

48 J.L.M. Vrancken, Parallel Object Oriented Term Rewriting : a first implementation in Pool2, September 1989

49 G.R. Renardel de Lavalette, Choice in applicative theories, September 1989

50 C.P.J. Koymans \& G.R. Renardel de Lavalette, Inductive definitions in COLD-K, September 1989

51 F. Voorbraak, Conditionals, probability, and belief revision (preliminary version), October 1989

52 A. Visser, On the $\Sigma_{1}^{0}$-Conservativity of $\Sigma_{1}^{0}$-Completeness, October 1989

53 G.R. Renardel de Lavalette, Counterexamples in applicative theories with choice, January 1990

54 D. van Dalen, L.E.J. Brouwer. Wiskundige en Mysticus, June 1990

55 F. Voorbraak, The logic of objective knowledge and rational belief, September 1990

56 J.L.M. Vrancken, Reflections on Parallel and Functional Languages, September 1990

57 A. Visser, An inside view of EXP, or: The closed fragment of the provability logic of $I \Delta_{0}+\Omega_{1}$, revised version with new appendices, October 1990

58 S. van Denneheuvel, K. Kwast, G.R. Renardel de Lavalette, E. Spaan, Query optimization using rewrite rules, October 1990

59 G.R. Renardel de Lavalette, Strictness analysis via abstract interpretation for recursively defined types, October 1990

60 C.F.M. Vermeulen, Sequence Semantics for Dynamic Predicate Logic, January 1991

61 M.B. Kalsbeek, Towards the Interpretability Logic of I $\triangle 0+E X P$, January 1991.

62 D. van Dalen, $I<R$, Some Intuitionistic Elementary Equivalences, February 1991.

63 M. Bezem, Strong termination of Logic Programs, March 1991.

64 A. Visser, The Unprovability of Small Inconsistency, March 1991. 